Self-Expansion in Intercultural Relationships: Cultural Integration as a Mechanism for the Association with Relationship Quality

\author{
Hanieh Naeimi
}

215353022

Department of Psychology, York University

PSYC 4001: Specialized Honours Thesis

Dr. Amy Muise

April 27, 2021 


\begin{abstract}
Intercultural romantic relationships, in which partners have different cultural backgrounds, are increasingly common. Intercultural marriages, however, remain relatively rare, accounting for only $5 \%$ of all unions in Canada. Intercultural couples may face additional barriers in maintaining their relationships over time, including reconciling their cultural and couple identities (identity integration) and communicating effectively about cultural differences (cultural inclusion). Despite these challenges, intercultural relationships may also provide opportunities for self-expansion - novelty or growth as a result of the relationship or a partner's culture. Across three studies we tested the prediction that self-expansion in intercultural relationships would be associated with higher relationship satisfaction and lower conflict through cultural integration processes. In Studies 1 and $2-$ a cross-sectional study of people in intercultural relationships $(N=242)$ and a dyadic study of intercultural couples $(N=312)$-we found that self-expansion (both in general, and specific to partners' cultures) was associated with higher relationship quality through greater integration and cultural inclusion. In Study 3-a preregistered experimental study $(N=342)$-we found that although people in a cultural selfexpansion group reported higher relationship satisfaction compared to a control group, cultural integration processes did not mediate this relationship. Our findings reveal that sharing cultural differences and novel experiences can be beneficial for intercultural couples, extending selfexpansion theory to intercultural relationships and providing insight into the maintenance of satisfaction over time.
\end{abstract}

Keywords: Self-expansion, intercultural relationships, identity integration, relationship quality 


\section{Self-Expansion in Intercultural Relationships: Cultural Integration as a Mechanism for the Associations with Relationship Quality}

Intercultural romantic relationships, in which partners have different cultural backgrounds, are becoming more common in multicultural societies (Levin et al., 2007; Rico et al., 2018). Despite this increase, intercultural marriages are still relatively rare. For example, in Canada, intercultural marriages (including intercultural common-law couples) only make up 5\% of all such unions (Statistics Canada, 2011). This suggests that intercultural couples may face additional barriers in maintaining their relationship over time (e.g., Herman \& Campbell, 2012), including family approval (Shenhav et al., 2017; Wang et al., 2006) and communicating effectively about cultural differences (Killian, 2013). In fact, the bulk of the previous research on intercultural relationships has primarily focused on the difficulties intercultural couples face as a result of their cultural differences (e.g., Karis \& Killian, 2011; Seshadri \& Knudson-Martin, 2013). In the current research, however, we aim to investigate the opportunities for growth in intercultural partnerships and how these opportunities are associated with relationship quality. More specifically, our aim is to test how cultural differences in relationships can provide opportunities for self-expansion-novelty or growth as a result of the partner or relationship (Aron \& Aron, 1986, 1996) — and in turn, how self-expansion in intercultural relationships might facilitate identity integration (integrating a person's couple identity with their cultural identity) and cultural inclusion (effectively communicating about culture in the relationship) to ultimately be associated with relationship satisfaction.

\section{Intercultural Relationships}

Culture is defined as a shared system of values, beliefs, customs, behaviours, and norms that is learned and transmitted across generations (Bustamante et al., 2011). Following this 
definition, an intercultural relationship involves partners from different cultural backgrounds, which can include different national, racial, ethnic, or religious identities (de Guzman \& Nishina, 2017; Reiter \& Gee, 2008; Troy et al., 2006). The bulk of the previous research on intercultural relationships has focused on interracial couples, most commonly couples in which one partner identified as White and the other partner as Black (Gaines et al., 2015; Seshadri \& KnudsonMartin, 2013). This means we currently have limited knowledge about couples in which partners identify as having different cultural identities but not different racial identities, such as an Iranian-Arab couple (de Guzman \& Nishina, 2017). Intercultural couples might be navigating other cultural differences beyond race, and using a broader definition of intercultural relationships can help shed some light on these differences.

Along the same lines, past research has regarded monocultural couples as normative and mostly studied the differences that exist between monocultural and intercultural couples (Gaines, 1997; Killian, 2001). Because of this focus on comparing across couple types, the bulk of the past research has mainly been on challenges intercultural couples face and how they act as barriers to the maintenance of these relationships. Many couples face interpersonal problems at some point during their relationships, however intercultural couples may face additional challenges that are unique to their cultural differences. For instance, Shenhav et al. (2017) found that a major source of conflict between college-aged students and their parents is their different attitudes towards intercultural dating. This increased parental conflict and lack of support might create additional strain on intercultural relationships. Related to concerns about parental acceptance, Wang et al. (2006) found that adolescents in interracial relationships are less willing to introduce their partners to their parents, and as such are more likely to break up. Additionally, people in intercultural relationships report sometimes being discouraged by their friends from 
marrying across race and ethnicity, even if those friends themselves are in intercultural marriages (Killian, 2001). Indeed, this lack of support and approval is not limited to families and friends but is pervasive throughout society. Skinner and Rae (2019) found that even though there has been an apparent improvement in social attitudes towards interracial couples, many still exhibit explicit and implicit biases against these unions. Thus, the stigma and lack of social approval can be considered external factors that lead to the dissolution of some intercultural relationships.

Despite these challenges, intercultural relationships may also provide individuals with unique opportunities for growth. People in an intercultural relationship may be presented with more instances to reflect on how culture influences their sense of self. That is, an intercultural relationship may increase the couple member's cultural self-awareness, which is associated with greater well-being (Lu \& Wan, 2018). Learning about a partner's culture and having novel experiences related to culture might provide opportunities for self-expansion and in turn, be associated with relationship quality.

\section{Self-Expansion Theory}

Self-expansion theory posits that people have an intrinsic motivation to expand their sense of self by seeking growth and novelty in order to increase their potential resources and broaden their perspectives (Aron \& Aron, 1986, 1996; Aron et al. 2003). For example, people often self-expand by taking up new hobbies, learning a new skill, or starting a new book. One key way that people self-expand is through their involvement in romantic relationships by incorporating the resources, perspectives, and identities of one's partner into the self (Aron et al. 1995; Aron et al. 2006). Self-expansion tends to be high in the early stages of relationships as partners are getting to know each other, but even partners in longer term relationships can continue to self-expand by engaging in novel shared activities (Aron \& Aron, 1986, 1996; Aron 
et al., 2000). Relational self-expansion is associated with positive feelings, and studies have shown that it protects against relational boredom and predicts relationship satisfaction and excitement. More specifically, higher self-expansion has been shown to result in higher relationship satisfaction and lower conflict (Aron \& Aron, 1996; Lewandowski \& Ackerman, 2006). Participating in self-expanding activities can help couples more successfully overcome conflict by exerting more effort in this process (Mattingly \& Lewandowski, 2013; Raposo et al., 2020), and emotional capital theory suggests that positive experiences in relationships can build up and aid in coping with relational challenges (Feeney \& Lemay, 2012; Raposo et al., 2020; Walsh et al., 2017). Accordingly, the benefits of self-expansion have been extended to include increased sexual desire and satisfaction (Muise et al., 2019), and lower levels of conflict and sexual distress in couples (Raposo et al., 2020), which may be attributed to positive selfexpanding experiences facilitating relationship maintenance behaviours.

Including aspects of a partner into a person's self-concept is theorized to be one mechanism through which self-expansion is associated with relationship satisfaction (Aron \& Aron, 1986; Aron et al., 1992; Aron et al., 2003) and in intercultural relationships this might extend to incorporating or integrating aspects of a partner's culture. In the current research, we aim to extend self-expansion theory to reframe the experiences of intercultural couples. Applying the self-expansion model, the differences between partners in intercultural relationships can be viewed as additional, unique opportunities to expand one's sense of self through experiencing each other's cultures. Following the sense of interdependence that is accompanied by selfexpansion, intercultural couples who report more self-expansion may feel more satisfied in their relationships and experience less conflict.

\section{Intercultural Relationships and Self-Expansion}


Given the past work on the benefits of self-expansion in relationships (e.g., Aron \& Aron, 1986, 1996; Aron et al., 2005; Muise et al., 2019), and the unique opportunities for growth that are offered by different cultures (e.g., Clark et al., 2015; Gaines \& Agnew, 2003) researchers have applied self-expansion theory to understand the process of intergroup friendships and interactions. For instance, in a series of studies by Paolini et al. (2016), people who were oriented towards self-expansion, were more interested in interacting with outgroup members. In addition, people who have a higher motivation to self-expand, have more positive interactions when they meet someone who identifies with a different ethnicity (Dys-Steenbergen et al., 2016). In fact, other research has shown that intercultural social contact improves creativity through cultural learning, which can lead to self-expansion (Lu et al., 2017).

A large body of research has found support for the benefits of intergroup contact, but most of this work has focused on interactions with unknown others from a different cultural background or on intergroup friendships. Yet intercultural romantic relationships are more complex because of the high level of interdependence and frequent contact across different domains, resulting in opportunities that are unique to romantic partnerships. As Aron et al. (2006) note, similarities and differences work together in relationship formation. On the one hand, similarity plays a role in relationship initiation in that it enhances intimacy. On the other hand, having a partner with different experiences can be valuable because it can offer opportunities to expand the self. More specifically, since individuals have an intrinsic motivation to pursue novelty, they may seek relationships with those who have different qualities or interests (Aron et al., 2006; Paolini et al., 2016). Still, these general differences are fundamentally different from cultural differences that are rooted in individuals' belief systems. 
Indeed, when partners have differences in attitudes and beliefs, this might provide them with opportunities to view the world in new ways and potentially help each partner grow.

One way that couples in intercultural relationships can have unique opportunities to selfexpand is through their cultural differences, which we refer to as cultural self-expansion.

Different cultures can offer different perspectives to individuals and allow them to expand their horizons. Given the benefits of self-expansion in relationships, intercultural couples may have access to more opportunities to self-expand through their cultural differences. In the current research, we consider both relational self-expansion in general as well as cultural-specific selfexpansion to understand how each might influence the process by which people integrate their culture into their relationship and in turn, their feelings of satisfaction.

\section{Self-Expansion and Couple-Cultural Identity Integration}

Self-expansion has been shown to be beneficial in romantic relationships, however we expect self-expansion in intercultural relationships might also be associated with partners integrating their cultural and couple identities. It is possible that identity integration, an adaptive strategy to negotiate multiple identities, is one process in intercultural relationships that accounts for the associations between self-expansion and relationship quality. People often hold multiple identities based on different aspects of their lives and experiences. Most relevant to the current research are a person's cultural identity, a sense of affiliation towards a cultural group and its values (Amiot et al., 2007; Yampolsky et al., 2020), and their couple identity, the feeling of belonging to a relationship, accompanied by a sense of we-ness that allows partners to express their uniqueness and independence (Fergus \& Reid, 2001; Reid et al., 2006; Yampolsky et al., 2020). People in intercultural relationships have different strategies to define themselves in terms of these two identities. The Cognitive-Developmental Model of Social Identity Integration 
(CDSMII; Amiot et al, 2007) has been applied to research with intercultural couples to assess numerous aspects of relationship quality and satisfaction (Yampolsky et al., 2020). This model lists different ways through which people reconcile their social identities. Some strategies such as categorization, which is defined as having one identity dominate over others with little to no overlap, and compartmentalization, which refers to simultaneously identifying with multiple identities and keeping them separate, tend to be associated with poorer well-being (Amiot et al., 2007; Yampolsky et al., 2016).

Another commonly used strategy is integration which is a process through which multiple identities become connected. Those applying this strategy recognize and cherish similarities between their identities and see differences as useful opportunities for growth. People who integrate their identities tend to see great overlap among them and are able to effectively resolve conflicts between their identities (Amiot et al., 2007; Yampolsky et al., 2020). Couples in which both partners have integrated their identities, make each other feel validated and willingly participate in the other partner's culture, while experiencing less unresolved conflict (Seshadri \& Knudson-Martin, 2013). Indeed, integration has received attention from researchers because of its importance in predicting well-being. Yampolsky et al. (2016) found that integration is associated with an increased sense of self-growth and identified social support as a potential facilitator to integration.

Identity integration and self-expansion seem to involve similar processes. Incorporating aspects of a partner into the self, an important mechanism in self-expansion, involves increasing the amount of overlap between two partners' identities. This resembles identity integration in which a cohesive identity is created as a result of merging couple and cultural identities. As such, 
we suggest that identity integration is one mechanism through which self-expansion is associated with relationship satisfaction in intercultural relationships.

\section{Self-Expansion and Cultural Inclusion in the Relationship}

Effective communication and feeling understood enhance intimate feelings in romantic relationships (Laurenceau, 1998). Communication may be especially important in intercultural relationships, in which misunderstandings are more likely to occur (Holoien et al., 2015). Killian (2013) has used the concept of cultural inclusion to refer to effective communication about culture between partners. This includes the extent to which intercultural couples include their cultures in their relationships and provide supportive communication to each other with regards to their cultural differences. Even though more research is needed to establish the benefits associated with this concept, successful intercultural couples are often aware of and curious about their differences (Ham, 2003; Ting-Toomey, 2011), which can be linked to a higher cultural inclusion.

Both identity integration and cultural inclusion involve similar processes aimed at increasing the amount of overlap between social identities. In the current project, cultural inclusion will be considered as a type of cultural integration at the interpersonal level, being at work between partners, whereas identity integration is an intrapersonal process within individuals' self-concepts. Further, cultural inclusion works in a similar way as the mechanism for self-expansion, through which individuals include aspects of their partners in the self. As such, we suspect that cultural inclusion is another process through which self-expansion leads to increased relationship satisfaction.

\section{The Current Studies}


In the current research we aim to better understand self-expansion in intercultural relationships and the unique processes that might account for the association between selfexpansion and relationship quality in these relationships. In this work, our goal is to be more inclusive through studying not only those whose cultures are clearly distinct, but any couple who identifies as being intercultural. In addition, differences in intercultural relationships are not just seen as sources of conflict, but opportunities for growth and effective communication. Following this view, we aim to investigate the cultural processes through which relational self-expansion and cultural self-expansion are associated with relationship satisfaction and conflict.

We predict that individuals who experience higher levels of relational and cultural selfexpansion will be more satisfied with their relationships and experience less conflict. We also hypothesize that people in intercultural relationships who report higher self-expansion will integrate their cultural and couple identities (identity integration) and will more effectively communicate about their cultures (cultural inclusion) and in turn, report higher relationship satisfaction, less conflict in general, and less culture-specific conflict. That is, we propose a mediation model in which identity integration and cultural inclusion account, in part, for the association between self-expansion and relationship satisfaction, conflict, and cultural conflict. These predictions will be tested in three studies using cross-sectional, longitudinal, and experimental designs.

\section{Study 1}

Study 1 was an initial attempt to test how self-expansion is associated with relationship quality in intercultural relationships. Using a cross-sectional design, we tested whether relational self-expansion (i.e., novelty, excitement, and broadening experienced through the partner or relationship) and cultural self-expansion (i.e., novelty, excitement, and broadening experienced 
as a result of a partner's culture or the couple's cultural differences) are linked to identity integration and cultural inclusion, and whether these factors are associated with relationship satisfaction, conflict, and cultural conflict in intercultural relationships.

\section{Method}

\section{Participants}

We recruited 249 participants who were in intercultural relationships through Prolific Academic, a crowdsourcing platform for research. To participate in this study, individuals had to be in an intercultural relationship of at least 6 months. Inclusion criteria were checked automatically by Prolific and confirmed in the beginning of the study. Seven participants were excluded from analyses because they failed at least three of the four attention checks throughout the study (e.g., "I believe I am paying attention so I will select 2"). Thus, the final sample included 242 participants (108 male, 126 female, 8 other, $\left.M_{\text {age }}=37.16, S D_{\text {age }}=9.99\right)$. The majority of the participants were married and living with their partner $(91.7 \%$, living together but not married: $5.4 \%$, in a committed relationship but not living together: $2.5 \%$, casually dating: $0.4 \%)$ and were together for an average of 10 years $(M=10$ years, $S D=7.97$ years $)$. The majority of participants (69.7\%) identified as White, 9.6\% identified as Latin American, 7.6\% identified as East Asian, 4.4\% identified as Black, 4\% identified as bi/multicultural, 2.8\% identified as South Asian, and 2\% indicated other.

\section{Procedure}

Participants first answered eligibility questions about their relationship status, length and type and those who did not meet the criteria were screened out. After providing consent, participants answered some demographic questions including questions about their and their partners' cultural backgrounds. The two items on racial/ethnic background had participants 
choose from 7 broad categories (e.g., White, Black, East Asian, etc.), and participants were asked to specify their background in an open text format. Participants' responses on these open-ended items were later checked to confirm the intercultural nature of their relationships. Several selfreport measures were used to assess relational and cultural self-expansion, identity integration, cultural inclusion, relationship satisfaction, conflict, and cultural conflict. Lastly, they were debriefed about the purpose of the study.

\section{Measures}

See Appendix below for full measures.

Self-Expansion. To assess relational self-expansion, the Self-Expansion Questionnaire (SEQ; Lewandowski \& Aron, 2002) made up of 14 items was used. Sample questions from this measure include "How much does your partner provide a source of exciting experiences?" and "How much do you feel that you have a larger perspective on things because of your partner?", answered on a 7-point scale from $1=$ Not very much to $7=$ Very much $(\alpha=.91, M=5.05, S D=$ .96). We adapted this measure of self-expansion to ask about cultural self-expansion. Examples of these adapted items include "How much does your partner's culture(s) provide a source of exciting experiences?" and "How much do you feel that you have a larger perspective on things because of being exposed to your partner's culture(s)?", answered on the same 7-point scale $(\alpha=$ $.93, M=4.97, S D=1.06)$.

Identity Integration. Participants were given a description of what couple and cultural identity mean, followed by a 27-item questionnaire. We adapted the Multicultural Identity Integration Scale (MULTIIS; Yampolsky et al., 2016) to reflect negotiations between couple and cultural identities. In the current study, the major focus was on identity integration and as such, only 8 items from this measure corresponding to integration were included in the analyses. An 
adapted item measuring the integration strategy includes "I have an identity that includes my cultural and couple identities". All items were rated on a 6 -point scale from $1=$ Not at all to $6=$ Mostly $(\alpha=.89, M=4.70, S D=1.18)$.

Cultural Inclusion. The Index of Cultural Inclusion (ICI) was developed by Killian (2013) to capture individuals' experiences within their relationships and how they perceive their partners' experiences. More specifically, it measures the extent to which couples engage in open and supportive communication about their cultural differences. This index includes 28 items such as "When I share very personal things about my cultural background, I never regret it afterward." and "My partner values my cultural or ethnic beliefs and customs" measured on a 7point scale from $1=$ Strongly disagree to $7=$ Strongly agree $(\alpha=.66, M=5.69, S D=0.91)$.

Relationship Quality. The Perceived Relationship Quality Component Inventory (PRQC; Fletcher et al., 2000) was administered to participants. This inventory assesses multiple aspects of relationship quality, including relationship satisfaction, commitment, intimacy, trust, passion, and love through 18 items on a 7 -point scale $(1=$ not at all, $7=$ extremely $)$. Of particular interest in this study was the relationship satisfaction subscale which includes three items such as "How happy are you with your relationship?" $(\alpha=.97, M=5.78, S D=1.31)$. We also assessed a negative indicator of relationship quality—conflict —using the 5-item Conflict Scale by Braiker and Kelly (1979) in which participants were asked about the frequency and intensity of conflict in the relationship. An example from this scale is "How often do you feel angry or resentful towards your partner?" measured on a 9-point scale, labelled according to the specific questions (e.g., $1=$ not at all, $9=$ very much so; $\alpha=.82, M=3.98, S D=1.69$ ). We adapted this scale to measure cultural conflict with the same 9-point scale, including items such 
as "How often do you feel angry or resentful toward your partner over cultural differences between you?" $(\alpha=.88, M=2.60, S D=1.60)$.

\section{Results}

We used SPSS 27.0 to conduct correlation and multiple regression analyses to test associations between self-expansion, identity integration, cultural inclusion, relationship satisfaction, and conflict. In the current study we test the associations between relational selfexpansion and cultural self-expansion separately, and then together in the same model, to determine if these have unique associations with our other variables of interest. We report partial correlations and zero-order correlations for all of the main variables to distinguish relational and cultural self-expansion as unique predictors of identity integration and cultural inclusion (see Table1).

\section{Self-Expansion and Relationship Quality}

In line with previous findings (e.g., Aron et al., 2000; Muise et al., 2019), higher relational self-expansion was associated with higher relationship satisfaction $(\beta=.88, t(237)=$ $12.87, p<.001,95 \% \mathrm{CI}[.75,1.02])$, and lower levels of conflict $(\beta=-.60, t(237)=-5.62, p$ $<.001,95 \%$ CI $[-.82,-.39])$, and cultural conflict $(\beta=-.44, t(237)=-4.21, p<.001,95 \%$ CI $[-$ $.65,-.24])$. These associations remained significant after controlling for cultural self-expansion: relationship satisfaction $(\beta=.98, t(237)=10.59, p<.001,95 \%$ CI $[.79,1.16])$, conflict $(\beta=-.83$, $t(237)=-.47, p<.001,95 \% \mathrm{CI}[-1.11,-.54])$ and cultural conflict $(\beta=-.571, t(237)=-4.03, p$ $<.001,95 \%$ CI [-.85, -.29]). Similarly, cultural self-expansion was also associated with higher relationship satisfaction $(\beta=.47, t(237)=6.21, p<.001,95 \%$ CI $[.32, .61])$, less conflict $(\beta=-$ $.21, t(237)=2.02, p<.05,95 \% \mathrm{CI}[-.41,-.01])$, and less cultural conflict $(\beta=-.16, t(237)=-$ $1.67, p>.05,95 \%$ CI $[-.36, .03])$. But only the association between cultural self-expansion and 
less conflict $(\beta=.29, t(237)=2.24, p<.05,95 \% \mathrm{CI}[.35, .55])$ remained significant when relational self-expansion was controlled for. Overall, these results suggest that while relational self-expansion is a strong and unique predictor of relationship quality, cultural self-expansion uniquely predicts associations with less conflict after controlling for its shared variance with relational self-expansion.

\section{Indirect Associations Between Self-Expansion and Relationship Satisfaction via Identity}

\section{Integration and Cultural Inclusion}

First to test our prediction that relational and cultural self-expansion would be associated with identity integration and cultural inclusion, we conducted two separate multiple regressions with relational and cultural self-expansion predicting identity integration and cultural inclusion. Both cultural and relational self-expansion were significantly associated with identity integration and cultural inclusion (see Table 1). Additionally, when entered as simultaneous predictors in multiple regression models, relational self-expansion was associated with greater identity integration $(\beta=.30, t(237)=3.02, p<.01,95 \% \mathrm{CI}[.10, .50])$ and cultural inclusion $(\beta=.39, t$ $(236)=5.10, p<.001,95 \%$ CI $[.24, .54])$, and although cultural self-expansion was not significantly associated with cultural inclusion $(\beta=.02, t(236)=.24, p>.05,95 \%$ CI $[-.12, .15])$, it was associated with greater identity integration $(\beta=.19, t(237)=2.08, p<.05,95 \% \mathrm{CI}$ $[.01, .37])$.

Next, to investigate the indirect associations between the two types of self-expansion and relationship quality (relationship satisfaction, general conflict, and cultural conflict) through identity integration and cultural inclusion, several mediation analyses were conducted with each of our outcomes (See Table 2 and Figure 1). We conducted simple mediation analyses with ordinary least squares using Hayes' PROCESS macro (version 3.5; Hayes, 2020) in SPSS 27.0. 
The coefficient estimates of the indirect effects with bias-corrected bootstrap $95 \%$ confidence intervals (5000 samples) for all models are mentioned in Tables 2 and 3. The results revealed that relational self-expansion was associated with greater relationship satisfaction in intercultural relationships through both greater identity integration (indirect effect $=.07 ; 95 \%$ CI $[0.01,0.13]$ ) and greater cultural inclusion (indirect effect $=.16$; 95\% CI $[0.07,0.28]$ ). Relational selfexpansion was also associated with lower conflict and cultural conflict only through cultural inclusion. In addition, through both identity integration and cultural inclusion, cultural selfexpansion was association with greater relationship satisfaction, less conflict, and less cultural conflict (see Table 2). It is important to note that cultural inclusion mediated the association between both relational and cultural self-expansion and all predictors of relationship quality. While identity integration also mediated the associations between cultural self-expansion and all indicators of relationship quality, it only mediated the association between relational selfexpansion and satisfaction (Table 2).

Additionally, when controlling for cultural self-expansion, relational self-expansion was associated with increased relationship satisfaction through both greater identity integration and greater cultural inclusion and was associated with lower conflict and lower cultural conflict only through cultural inclusion. When controlling for relational self-expansion, there were no indirect associations between cultural self-expansion and any of our outcome variables (Table 3).

\section{Study 2}

In Study 2, we aimed to extend the findings of Study 1 by recruiting both partners in intercultural couples, given that one partner's experiences of self-expansion could influence the other partner's relationship quality. Our goal was to test whether self-expansion is indirectly linked to both partners' relationship satisfaction, conflict, and cultural conflict through identity 
integration and cultural inclusion. We predicted that a person's degree of relational and cultural self-expansion would predict their and their partners' identity integration and cultural inclusion, and in turn, higher relationship satisfaction, lower conflict, and cultural conflict for both partners. In addition, to test our effects over time, we followed up with both partners four to six months after the initial survey to test whether self-expansion predicts changes in cultural integration and inclusion over time, and in turn relationship satisfaction, conflict, and cultural conflict.

\section{Method}

\section{Participants}

We recruited 166 couples on Prolific to participate in the survey. To be eligible, couples had to be in an intercultural relationship of at least 6 months. Inclusion criteria were confirmed in the beginning of the study. Of the interested couples, 10 couples were excluded from analyses because they failed more than 1 of the 4 attention checks $(N=10)$, did not provide post-debrief consent $(N=1)$, or their partner was excluded for these reasons $(N=9)$. The final sample included 156 couples ( $N=312$ participants; 146 males, 159 females, 7 other), who were 36 years old on average $\left(M_{\text {age }}=35.63, S D_{\text {age }}=9.13\right)$ and mostly married $(93.3 \%)$ and living together (97.8\%). On average couples had been together for 9 years $(M=8.98, S D=6.25)$. The racial/ethnic backgrounds of the participants were as follows: $68.5 \%$ identified as White, $8.5 \%$ identified as Latin American, 6.9\% identified as East Asian, 4.6\% identified as South Asian, $4.6 \%$ identified as bi/multicultural, $4.3 \%$ identified as Black, and $2.6 \%$ specified their cultures as other.

Of the participants who completed the first survey, 57\% completed the second survey four to six months later ( $N=177 ; 85$ males, 89 females, 3 other). We compared participants who did versus did not participate in the follow-up survey on all of our key variables using a 
MANOVA. Participants did not differ on any of the key variables, except for relationship satisfaction $(p=.043)$ in that those who participated in the follow-up survey reported higher relationship satisfaction $(M=6.21, S E=.08)$ compared to those who did not participate $(M=$ 5.95, $S E=.09)$.

\section{Procedure}

Both members of couples were recruited for a two-part study on Prolific. Participants' eligibility was checked once automatically by Prolific and once in the beginning of the study. Members of the couple completed two separate surveys with identical measures. First, they provided their consent, and then continued to answer questions on relational and cultural selfexpansion, identity integration, cultural inclusion, relationship satisfaction, general and cultural conflict. Lastly, they answered some demographic questions, including questions about their cultural background similar to Study 1, were debriefed and asked for a post-debrief consent. Approximately four to six months later, all participants were invited to complete a second survey. All participants who responded to Time 2 were still in a relationship with their partner.

\section{Measures}

We used the same measures as Study 1, but they were answered by both partners.

Relational self-expansion $(\alpha=.91, M=5.26, S D=.98)$ and cultural self-expansion $(\alpha=.94, M$ $=4.89, S D=1.20)$ were each measured using the SEQ and its adapted version on a 7-item scale (Lewandowski \& Aron, 2002). To measure identity integration and cultural inclusion, the same items from the MULTIIS scale (Yampolsky et al., 2016; $\alpha=.83, M=4.23, S D=.90$ ) and the ICI (Killian, 2003; $\alpha=.92, M=5.77, S D=.79$ ) were used. Relationship satisfaction was measured using the satisfaction subscale from the PRQC (Fletcher et al., 2000; $\alpha=.97, M=$ 
$6.10, S D=1.09)$ and conflict $(\alpha=.77, M=3.89, S D=1.56)$ and cultural conflict $(\alpha=.85, M=$

$2.50, S D=1.53)$ were measured using the same scales (Braiker \& Kelly,1979).

\section{Results}

\section{Data Analytic Plan}

We used multilevel modeling with mixed models in SPSS 27.0. We tested a two-level model in which participants were nested within dyads. Our analyses were guided by the Actor Partner Interdependence Model (APIM) in which both partners' scores were regarded as simultaneous predictors (Kenny et al., 2006). Mediation analyses were conducted using multilevel modeling through the Monte Carlo Method for Assessing Mediation (MCMAM; Selig \& Preacher, 2008) with 20,000 resamples. 95\% confidence intervals were obtained and those intervals that did not contain zero indicated a significant indirect effect. The correlations between all variables can be found in Table 4.

\section{Indirect Associations Between Self-Expansion and Relationship Satisfaction via Identity Integration and Cultural Inclusion}

Consistent with our predictions, when a person reported higher relational self-expansion, they also reported higher levels of relationship satisfaction, lower conflict and cultural conflict, but there were no direct associations with a partner's outcomes. Additionally, when a person reported higher cultural self-expansion, they also reported higher relationship satisfaction and lower conflict, but not lower cultural conflict, and no direct associations with a partner's outcomes (Table 5). The associations between a person's relational and cultural self-expansion and their own identity integration and cultural inclusion were significant (see Table 5) but were only marginally associated with a partner's identity integration and cultural inclusion. As such, 
we only tested actor's identity integration and cultural inclusion as mediators between actor's relational and cultural self-expansion and their own and partner outcomes.

As mentioned in Table 5, people who reported higher relational self-expansion integrated their couple and cultural identities and in turn, their partner reported higher relationship satisfaction and less cultural conflict. Additionally, people who reported higher relationship selfexpansion were more apt to have positive, supportive communication about their cultures in the relationship (higher cultural inclusion) and in turn, reported higher relationship satisfaction and their partner reported lower conflict and cultural conflict.

Further, greater cultural self-expansion was associated with couple-cultural identity integration and in turn, both partners reported higher relationship satisfaction and their partner reported lower cultural conflict. In addition, cultural self-expansion was associated with people better integrating their cultures into their relationships and in turn, feeling more satisfied, experiencing less conflict and both partners reporting less conflict related to cultural differences.

Given the high correlation between relational and cultural self-expansion, when entered together as predictors in the model, not all of the effects remained (see Table 6). When both cultural and relational self-expansion were entered as predictors, relational self-expansion was associated with higher satisfaction through cultural inclusion, as well as lower conflict, and lower cultural conflict. In these models, cultural self-expansion was associated with higher levels of cultural conflict through identity integration (see Table 6 for all models).

\section{Associations Over Time}

Next, we tested whether associations between relational and cultural self-expansion persisted over time. That is, we tested whether greater self-expansion as reported in the first survey was associated with greater relationship satisfaction, cultural integration, and lower 
conflict over time, controlling for these at background. When a person reported higher relational self-expansion at baseline, they reported less conflict and their partner reported feeling more satisfied over time, accounting for these variables at baseline. In addition, when a person reported higher cultural self-expansion at baseline, their partner reported less general and cultural conflict over time (Table 7).

In the follow up survey, we found that when a person reported higher relational selfexpansion at baseline, their partner reported more satisfaction over time accounting for their own satisfaction at baseline $(\beta=0.27, t(168.32)=3.18, p<.01,95 \%$ CI $[.10, .44])$. Additionally, we found that when a person reported higher levels of cultural self-expansion at baseline, their partner reported greater integration between their couple and cultural identities over time, accounting for their integration at baseline $(\beta=0.15, t(170.09)=2.16, p<.05,95 \% \mathrm{CI}[.01$, .29]). However, identity integration and cultural inclusion did not significantly mediate the relationship between any of our main variables over time. We also entered relational and cultural self-expansion as simultaneous predictors in our models. In these models, only the associations between a person's relational self-expansion and their partner's identity integration and relationship satisfaction remained over time (see Table 8).

\section{Study 3}

In Study 3 we conducted a pre-registered experimental study designed to provide causal evidence for our predicted associations. In this study, we randomly assigned participants to one of three conditions, two experimental and one control. In the two experimental conditions, participants were presented with magazine articles about the positive effects of self-expansion or cultural self-expansion and were then instructed to participate in either a novel activity or a novel 
cultural activity over the upcoming weekend. After 72 hours, we followed up with participants to ask about their experiences over the weekend and to complete our key measures.

\section{Method}

\section{Participants}

We recruited 468 participants from Prolific Academic to participate in a two-part study. Eligible participants had to be in a cohabiting intercultural romantic relationship of 5 years or less, and currently living in Canada, the United States of America, or the United Kingdom. These criteria were checked automatically by Prolific and confirmed at the beginning of the survey. Participants were offered $£ 3.51$ (\$6.08 CAD/4.81USD) as compensation for both surveys. We excluded 126 participants who: did not meet our inclusion criteria $(N=3)$, did not provide postdebrief consent $(N=2)$, reported that they or their partner had a COVID-19 diagnosis which may have prevented them from engaging in the instructed activity $(N=2)$, failed to follow the experimental instructions $(N=48)$, or did not participate in the second part of the survey $(N=$ 71). Thus, the final sample consisted of 342 participants (193 females, 147 males, 2 other) who were on average 28 years old $\left(M_{\text {age }}=27.87, S D_{\text {age }}=6.58\right)$, mostly not married or engaged $(64.6 \%, 21.3 \%$ married, $13.7 \%$ engaged) and had been with their partner for an average of 2.55 years $(S D=1.25$ years $)$. The racial/ethnic backgrounds of the participants were as follows: $59.6 \%$ identified as White, $13.5 \%$ identified as East Asian, $10.5 \%$ identified as bi/multicultural, 6.4\% identified as Latin American, 5.3\% identified as Black, 4.4\% identified as South Asian, and $0.3 \%$ specified their cultures as other.

\section{Procedure}

The first survey was sent to participants on a Friday morning, while the second was sent the following Monday. In the initial survey, participants were first screened for their relationship 
status, length, type, and country of residence, and those who did not meet the criteria were screened out. After acquiring consent, individuals reported on some demographic questions in detail such as gender, age, and relationship length, as well as their relationship satisfaction. At this point, participants were randomly assigned to one of the three conditions: relational selfexpansion $(N=115)$, cultural self-expansion $(N=101)$, or control $(N=126)$.

Adapted from an existing manipulation (Muise et al., 2019), in the relational selfexpansion condition, participants read a fabricated article ostensibly from the University of Toronto Magazine, which talked about the benefits of self-expansion in cohabiting relationships. Following this, participants were instructed to engage in novel experiences with their partner over the upcoming weekend. In the cultural self-expansion condition participants read a comparable article about the benefits of self-expansion in intercultural relationships and were instructed to pursue novel experiences involving their own or their partners' cultures over the upcoming weekend (see Appendix below for both magazine articles). Lastly, participants in the control group received no article and were instructed to participate in typical activities with their partner over the upcoming weekend. All participants were told they would receive the second part of the survey in 72 hours.

The second survey included a manipulation check asking participants to reiterate the instructions they were given and asked them for some example activities they had engaged in over the weekend. All participants continued to answer questions about their current feelings of relationship satisfaction, conflict, cultural conflict, cultural inclusion, and cultural integration. Demographic questions regarding cultural backgrounds of participants and their partners were asked on the second survey, as to not over-focus on culture prior to the manipulation. Finally, the 
participants were debriefed in full about the fabricated article and the purpose of the research and were given a post-debrief consent form.

\section{Measures}

Shortened versions of the same measures used in Studies 1 and 2 were collected. Participants answered questions about their own and their partners' cultural backgrounds. First, as a manipulation check to ensure participants remembered and followed the instructions for their condition, we asked them to write out what they were instructed to do and what they did over the weekend. Overall, 48 participants were removed because they didn't remember the instructions and/or failed to follow them correctly (exclusions per condition were as follows: 16 from relational self-expansion, 27 from cultural self-expansion, 5 from control).

As an additional manipulation check, to test whether our experimental conditions boosted relational and cultural self-expansion as intended, post-manipulation we assessed relational self-expansion $(M=4.59, S D=1.68)$ and cultural self-expansion $(M=3.68, S D=$ 1.94) using two face-valid measures from the SEQ (Lewandowski \& Aron, 2002, and adapted for cultural self-expansion) on the same 7-point scale as Studies 1 and 2: "over the weekend, how much did being with your partner provide you with new experiences" and "over the weekend, how much did being with your partner provide you with new cultural experiences”. We assessed identity integration and cultural inclusion using the MULTIIS (Yampolsky et al., 2016) and ICI (Killian, 2013) respectively. Four items from the MULTIIS scale were used to measure integration with the same 6 -point scale $(\alpha=.82, M=4.33, S D=1.07)$. For cultural inclusion to keep the survey brief 10 items were selected out of the 28 to be administered on the second survey $(\alpha=.85, M=5.90, S D=.85)$ using the same 7-point scale. 
Relationship satisfaction was measured using the satisfaction subscale of the PRQC (Fletcher et al., 2000) and the conflict and modified cultural conflict scales were administered (Braiker \& Kelly, 1979). The satisfaction subscale was administered in full on the first survey ( $\alpha$ $=.96, M=6.19, S D=1.02$ ) and one representative item was assessed in the post-manipulation survey ("Over the past weekend, how satisfied were you with your relationship?"; $M=6.23, S D$ $=1.02)$. Lastly, three items from the conflict scale $(\alpha=.84, M=2.30, S D=1.52)$ and three items from the modified cultural conflict scale $(\alpha=.83, M=1.52, S D=1.15)$ were assessed in the post-manipulation survey, using the same 9-point scale as in previous studies.

\section{Results}

First, we conducted a manipulation check to test whether those assigned to the relational and cultural self-expansion condition reported having more novel experiences than those in the control condition. The results of an analysis of variance (ANOVA) showed that there were significant differences across these groups $(F(2,341)=37.99, p<.001)$, with participants in the relational self-expansion condition $(M=5.22, S D=1.39, p<.001)$ and the cultural selfexpansion condition $(M=5.05, S D=1.40, p<.001)$ reporting more novel experiences than those in the control group $(M=3.66, S D=1.72)$. Participants in the relational self-expansion and cultural self-expansion groups did not differ on the extent to which they reported engaging in novel activities over the previous weekend $(p=.42)$. The three groups also significantly differed $(F(2,341)=51.79, p<.001)$ on the extent to which they reported novelty from culture-specific experiences over the weekend. As expected, those in the cultural self-expansion group $(M=5.07$, $S D=1.41$ ) reported more culturally specific novel experiences compared to those in the relational self-expansion condition $(M=3.43, S D=1.80, p<.001)$ or those in the control condition $(M=2.80, S D=1.81, p<.001)$. People in the relational self-expansion group did 
however, report more culture-specific novel experiences compared to the control group $(p=$ $.004)$.

\section{Self-Expansion and Relationship Quality}

To test our key predictions, we conducted several univariate ANOVAs with condition as the independent variable and relationship satisfaction, conflict, cultural conflict, identity integration, and cultural inclusion (at the post-manipulation follow-up) as the dependent variables. Participants across conditions differed in relationship satisfaction $(F(2,341)=3.43, p$ $<.05)$, but did not report differences in conflict $(F(2,341)=1.67, p=.189)$, cultural conflict $(F$ $(2,341)=.152, p=.859)$, identity integration $(F(2,341)=.433, p=.649)$, or cultural inclusion

$(F(2,341)=.359, p=.699)$. More specifically, those in the cultural self-expansion condition $(M$ $=6.43, S D=.77)$ reported higher relationship satisfaction compared to those in the control group $(M=6.07, S D=1.13, p<.01)$ but not compared to those in the relational self-expansion group $(M=6.22, S D=1.07, p=.133)$. There were no differences between the relational self-expansion and control groups in relationship satisfaction $(p=.265)$.

\section{Indirect Associations Between Self-Expansion and Relationship Satisfaction via Identity Integration and Cultural Inclusion}

Since there were no main effects of condition on either of the mediators - identity integration and cultural inclusion-we did not expect any indirect effects. However, we ran our pre-registered mediations to test how identity integration and cultural inclusion assessed postmanipulation were associated with our key outcomes. We conducted mediation analyses (model 4) using Hayes' PROCESS macro (version 3.5; Hayes, 2020). As previously reported, people in the cultural self-expansion condition did not differ from those in the relational self-expansion condition $(b=-.04, S E=.12, t(2,342)=-.35, p=.73,95 \% \mathrm{CI}[-.27, .19])$ or those in the control 
condition $(b=-.09, S E=.11, t(2,342)=-.84, p=.40,95 \% \mathrm{CI}[-.32, .13])$ in terms of cultural inclusion. Further, identity integration did not significantly differ between those in the cultural self-expansion condition and those in the relational self-expansion $(b=-.13, S E=.15, t(2,342)=$ $-.89, p=.38,95 \% \mathrm{CI}[-.42, .16])$ or control conditions $(b=-.10, S E=.14, t(2,342)=-.74, p=.46$, 95\% CI[-.39,.18]). As such there were no significant indirect effects of our mediators. Although relationship satisfaction was significantly higher in the cultural self-expansion condition compared to the control condition, the effect was not mediated by cultural inclusion (95\% CI[$.16, .05])$ or identity integration $(95 \% \mathrm{CI}[-.10, .04])$.

However, we did replicate the associations between identity integration and cultural inclusion and our key outcome variables post-manipulation. More specifically, cultural inclusion was associated with greater relationship satisfaction $(b=.50, S E=.06, t(2,342)=8.52, p<.001$, $95 \% \mathrm{CI}[38, .61])$, lower conflict $(b=-.56, \mathrm{SE}=.09, t(2,342)=-6.02, p<.001,95 \% \mathrm{CI}[-.74,-$ $.37])$, and lower cultural conflict $(b=-.48, S E=.07, t(2,342)=-6.96, p<.001,95 \%$ CI[-.61, .34]). Similarly, identity integration was associated with higher relationship satisfaction $(b=.25$, $S E=.05, t(2,342)=5.09, p<.001,95 \% \mathrm{CI}[.15, .35])$, lower conflict $(b=-.20, S E=.08, t(2,342)$ $=-2.56, p<.05,95 \% \mathrm{CI}[-.35,-.04])$, but was not significantly associated with cultural conflict $(b$ $=-.09, S E=.06, t(2,342)=-1.59, p=.11,95 \% \mathrm{CI}[-.21, .02])$.

\section{General Discussion}

Intercultural relationships are increasingly common, but the bulk of the research on these relationships has focused on the challenges faced when merging two cultures. In the current set of studies, we focused on intercultural relationships as opportunities for growth by testing the associations between relational and cultural self-expansion and relationship quality. Our results replicated past research that has demonstrated that relational self-expansion is associated with 
higher relationship satisfaction and lower conflict (e.g., Aron et al., 2000; Muise et al., 2019), but extended these findings to intercultural couples and tested cultural integration processes as novel mechanisms for these associations. Across all studies we found that when couples reported high self-expansion in their relationships (Studies 1 and 2) or were instructed to engage in selfexpanding activities (Study 3), they reported higher relationship satisfaction. In Studies 1 and 2, we found that self-expanding through one's relationship and through a partner's culture were associated with greater integration of couple and cultural identities (identity integration), and more supportive communication about cultural differences in the relationship (cultural inclusion), and in turn higher relationship quality. In Study 3, intercultural couples who were instructed to engage in self-expanding activities related to their own or their partner's cultures, reported higher relationship satisfaction compared to a control group, and similar levels of relationship satisfaction to a group who were instructed to engage in novel activities with their partner more generally.

\section{Extending Self-Expansion Theory to Intercultural Relationships}

Self-expansion theory posits that seeking novelty is an internal motivation, and pursuing romantic relationships is one way through which individuals self-expand (Aron et al., 2013; Muise et al., 2019). The current findings are consistent with a large and growing body of research demonstrating the benefits of self-expansion for relationship quality (e.g., Harasymchuk et al., 2020; Mattingly et al., 2019, Muise et al., 2019; Raposo et al., 2020). However, the current set of studies extend previous research on self-expansion to intercultural relationships, and, for the first time, provide evidence for the benefits of cultural self-expansion as a unique process, separate from relational self-expansion. In addition, the current findings suggest that in intercultural relationships, unique mechanisms such as identity integration (incorporating one's 
couple and cultural identities) and cultural inclusion (creating an inclusive climate to discuss cultural differences in the relationship) account for the association between self-expansion and relationship quality. It is possible then that certain relationship processes have different mechanisms in intercultural relationships. Past work has illustrated that having a strong cultural identity is predictive of greater relationship quality in intercultural relationships (e.g., Brooks et al., 2021; Leslie \& Letiecq, 2004) and the current work is among a few that showcases the importance of an integrated couple and cultural identity for relationship quality (see Yampolsky et al., 2020).

A key extension of the current set of studies is that we aimed to assess self-expansion specifically related to cultural differences or novel cultural experiences (i.e., cultural selfexpansion). Previous research has shown that people higher in self-expansion are more interested in interacting and have more positive interactions with people from different cultural backgrounds (Dys-Steenbergen et al., 2016; Paolini et al., 2016), but no work had specifically investigated self-expansion related to these cultural differences. In our two correlational studies, Studies 1 and 2, cultural self-expansion was highly overlapping with relational self-expansion. As such, although they were each independently associated with our key outcomes, in models when they were entered as simultaneous predictors, there were fewer effects of cultural selfexpansion above and beyond relational self-expansion more generally. In Study 3, we were able to distinguish relational and cultural self-expansion from each other and demonstrated that people in the cultural self-expansion group who were instructed to participate in novel activities involving culture reported higher relationship satisfaction compared to those in the control condition (and to a similar degree as those in the relational self-expansion condition, which was not significantly different from the control group). The findings of Study 3 suggest that novel 
activities involving partners' cultures might have important functions for satisfaction in intercultural relationships.

Although self-expansion is a dyadic process in relationships, few studies have looked at how one partner's feelings of self-expansion influence the other partner's relationship satisfaction (for exceptions see Muise et al., 2019; Raposo et al., 2020), and no studies have investigated these processes in intercultural couples. In Study 2, we included both members of couples and examined dyadic associations between both relational and cultural self-expansion and relationship quality outcomes. The results showed that a person's experience of selfexpansion in the relationship, is associated with a partner's higher satisfaction, lower conflict, and lower cultural conflict through cultural integration processes. That is, people who report higher self-expansion in an intercultural relationship tend to better integrate their couple and cultural identities and in turn, their partner feels more satisfied and reports less conflict in the relationship. This may suggest that insomuch as self-expansion in intercultural relationships helps people better incorporate their cultures in the couple relationship, it can be beneficial, not only for that person, but for their romantic partner. These findings are consistent with previous research demonstrating that when engaging in a shared self-expanding activity, one partner's feelings of self-expansion can be associated with their partner's sexual desire and relationship satisfaction, above and beyond the partner's own feelings of self-expansion (Muise et al., 2019). In Study 2 in which we were able to follow up with couples after several months in their relationships, we found that those who reported higher self-expansion when they began the study, had partners who reported increases in satisfaction and decreases in conflict and cultural conflict over time, providing initial evidence that self-expansion might also help intercultural couples maintain their relationships over time. 
Interestingly, in Study 2 we found that self-expansion through a partner's culture was associated with more conflict related to cultural differences. It is possible that sharing one's culture with a partner can pose some challenges and may involve having difficult conversations about cultural differences. Previous work has shown that it is especially problematic when intercultural couples avoid talking about their cultural differences or when they prioritize one partner's culture over the other (Seshadri \& Knudson-Martin, 2013). Therefore, although discussing cultural differences in a relationship can be challenging, it also seems that these discussions can allow couples to negotiate differences and capitalize on opportunities for growth, which are associated with relationship quality (Gable \& Haidt, 2005; Gable et al., 2004).

It is important to note that we did find some differences across studies, especially in terms of the findings in the correlational studies compared to the experimental study. Although in the correlational studies we generally found evidence that self-expansion was associated with relationship quality through identity integration and cultural inclusion, in the experimental study, we did not find evidence for our mediation models. In Study 3, people who were instructed to engage in culturally self-expanding activities reported higher relationship satisfaction compared to the control group, but not lower conflict, and importantly there were no effects on culturalcouple integration or cultural inclusion in the relationship. There are a few reasons why manipulated self-expansion did not increase these cultural processes in relationships. First, on average, participants (regardless of their assigned condition) reported high levels of identity integration and cultural inclusion, and for many participants, there was not a lot of room to increase these further. Given that all of the participants were in established relationships, they may have already done a lot to integrate their own or their partner's culture into the relationship. Second, it is also possible that these cultural processes take longer to develop in a relationship 
and a weekend is not enough time to meaningfully change identity integration or create a culturally inclusive climate in the relationship. Future research could explore these processes in new couples and over a longer period of time.

\section{Limitations and Future Directions}

Despite the strengths of the current set of studies, including the use of multiple methods and the focus on an under researched population, there are several limitations. First, the majority of our participants were in established long-term relationships and were mostly married (Studies 1 and 2). Although in Study 3 we aimed to recruit people who were in newer relationships (less than 5 years), participants had to live with their partner in order to follow our manipulation instructions due to the COVID-19 pandemic, therefore, they were all cohabitating couples. People in established intercultural relationships have had a long time to negotiate their cultural differences and on average reported high levels of couple-cultural integration and largely already had a supportive environment for discussing their cultural differences. In future research, recruiting intercultural couples in the earlier stages of their relationship when they are first negotiating these differences could provide additional insights into these processes and how they are associated with relationship satisfaction and maintenance. Recruiting a sample of newer couples could also help test and provide additional evidence for the direction of the associations. Although we predicted and provided some support for the idea that self-expansion leads to relationship quality and cultural integration processes, it is also possible that intercultural couples who are more satisfied are more likely to self-expand and integrate their cultures. Following newer couples over time as they develop their relationships could provide further insight into these processes. 
Second, because we used a broad definition of intercultural couples, that included having different cultural, ethnic, or national identities, our samples were not as ethnically diverse as expected. In fact, our samples mostly consisted of people who identified their ethnicity as White, and some reported on partners who also identified as White. Although all participants in our studies had different cultural backgrounds from their partners, many had the same ethnicity. It is possible that these processes might differ for partners who have different ethnic identities or who have larger differences in their cultures and these results may not be generalizable to all intercultural couples. Indeed, evidence from studies on acculturating individuals shows that the larger the cultural difference, the more difficulties travelers and immigrants face adapting to the new culture (Dunbar, 1994; Furnham \& Bochner, 1982). This is because the more dissimilar two cultures are, the more people have to adapt and face challenges in the process (Demes $\&$ Geeraert, 2014). Individuals in intercultural relationships may also face more difficulties when their partner's culture is more dissimilar to their own, or when one or both partners belong to minority cultures. However, previous research also finds that people who enter interracial relationships in which partners have distinct identities are higher in openness to experience (Lee et al., 2017) compared to those who enter monocultural relationships, which could mean they have more interest in self-expanding through their relationships. Thus, future studies should aim to recruit more diverse samples and investigate the effects of cultural distance and majority/minority cultural memberships in these processes.

\section{Implications and Conclusions}

The current research expands our understanding of the processes involved in the maintenance of intercultural relationships. Previous work on intercultural relationships had primarily focused on interracial couples and there was limited research on the processes involved 
in the maintenance of successful intercultural relationships. Our work suggests that shared novel activities in intercultural relationships (inclusive of partners with different ethnic, national and cultural identities), is associated with higher satisfaction, integration of couple and cultural identities, and more supportive communication about cultural differences in the relationship. These studies illustrated the benefits of self-expansion in fostering identity integration and cultural inclusion, which have both been previously linked to increased personal and relational well-being (e.g., Amiot et al., 2007; Killian, 2013; Yampolsky et al., 2013). Given that intercultural couples face additional barriers compared to monocultural couples (e.g., Herman \& Campbell, 2012), this work is especially important in identifying the protective factors that may help intercultural couples maintain happier relationships.

In sum, across two correlational studies of people in intercultural relationship and intercultural couples followed over time, we found support for our predictions that relational and cultural self-expansion are associated with greater satisfaction and lower conflict through identity integration and cultural inclusion in the relationship. Our experimental study partially supported these predictions. Although identity integration and cultural inclusion were associated with more satisfaction and less conflict in these relationships, we were unable to adequately change the inclusive climate of the relationships with our manipulation to see the predicted indirect effects. We did, however find that engaging in cultural self-expansion was associated with higher relationship satisfaction, suggesting that sharing cultural differences and experiences can be beneficial for intercultural relationships. 


\section{References}

Amiot, C. E., de la Sablonniere, R., Terry, D. J., \& Smith, J. R. (2007). Integration of social identities in the self: Toward a cognitive-developmental model. Personality and Social Psychology Review, 11(4), 364-388. https://doi.org/10.1177/1088868307304091

Aron, A., \& Aron, E. N. (1986). Love and the expansion of self: Understanding attraction and satisfaction. New York: Hemisphere.

Aron, A., Aron, E. N., \& Smollan, D. (1992). Inclusion of Other in the Self Scale and the structure of interpersonal closeness. Journal of Personality and Social Psychology, 63, 596-612. http://dx.doi.org/10.1037/0022-3514.63.4.596

Aron, A., Fisher, H., Mashek, D. J., Strong, G., Li, H., \& Brown, L. L. (2005). Reward, motivation, and emotion systems associated with early stage intense romantic love. Journal of Neurophysiology, 94, 327-337. http://dx.doi.org/10.1152/jn.00838.2004

Aron, A., Lewandowski, G. W., Jr., Mashek, D., \& Aron, E. N. (2003). The self-expansion model of motivation and cognition in close relationships. In J. A. Simpson \& L. Campbell (Eds.), The Oxford handbook of close relationships (pp. 90-115). New York, NY: Oxford University Press. http://dx.doi.org/10.1093/oxfordhb/9780195398694.013.0005

Aron, A., Lewandowski, G. W., Jr., Mashek, D., \& Aron, E. N. (2013). The self-expansion model of motivation and cognition in close relationships. In J. A. Simpson \& L. Campbell (Eds.), The Oxford handbook of close relationships (pp. 90-115). New York, NY: Oxford University Press. http://dx.doi.org/10.1093/oxfordhb/9780195398694.013.0005 
Aron, A., Norman, C. C., Aron, E. N., McKenna, C., \& Heyman, R. E. (2000). Couples'shared participation in novel and arousing activities and experienced relationship quality. Journal of Personality and Social Psychology, 78, 273-284. http://dx.doi.org/10.1037/0022-3514.78.2.273

Aron, A., Paris, M., \& Aron, E. N. (1995). Falling in love: Prospective studies of self-concept change. Journal of Personality and Social Psychology, 69, 1102-1112. http://dx.doi.org/10.1037/0022-3514.69.6.1102

Aron, A., Steele, J. L., Kashdan, T. B., \& Perez, M. (2006). When similars do not attract: Tests of a prediction from the self-expansion model. Personal Relationships, 13(4), 387-396. http://dx.doi.org.ezproxy.library.yorku.ca/10.1111/j.1475-6811.2006.00125.x

Aron, E. N., \& Aron, A. (1996). Love and the expansion of the self: The state of the model. Personal Relationships, 3, 45-58. http://dx.doi.org/10.1111/j.1475-6811.1996.tb00103.x

Braiker, H., \& Kelley, H. (1979). Conflict in the development of close relationships. In R. Burgess \& T. Huston (Eds.), Social exchange in developing relationships. New York, NY: Academic Press.

Brooks, J. E., Ly, L.M., \& Brady, S.E. (2021). Race talk: How racial worldview impacts discussions in interracial relationships [Manuscript in preparation]. Department of psychology, Indiana University Bloomington.

Bustamante, R. M., Nelson, J. A., Henriksen, R. C., Jr., \& Monakes, S. (2011). Intercultural couples: Coping with culture-related stressors. The Family Journal, 19(2), 154-164. http://dx.doi.org.ezproxy.library.yorku.ca/10.1177/1066480711399723

Clark, E.M., Harris, A.L., Hasan, M., Votaw, K.B. \& Fernandez, P. (2015). Concluding Thoughts: Interethnic Marriage through the Lens of Interdependence Theory. Journal of Social Issues, 71(4), 821-833. https://doi.org/10.1111/josi.12151 
de Guzman, N. S., \& Nishina, A. (2017). 50 Years of Loving: Interracial Romantic Relationships and Recommendations for Future Research. Journal of Family Theory \& Review, 9(4), 557-571. https://doi.org/10.1111/jftr.12215

Demes, K. A., \& Geeraert, N. (2014). Measures matter: Scales for adaptation, cultural distance, and acculturation orientation revisited. Journal of Cross-Cultural Psychology, 45(1), 91109. https://doi.org/10.1177/0022022113487590

Dunbar, E. (1994). The German executive in the U.S. work and social environment: Exploring role demands. International Journal of Intercultural Relations, 16, 1-16. http://dx.doi.org.ezproxy.library.yorku.ca/10.1016/0147-1767(94)90034-5

Dys-Steenbergen, O., Wright, S. C., \& Aron, A. (2016). Self-expansion motivation improves cross-group interactions and enhances self-growth. Group Processes \& Intergroup Relations, 19(1), 60-71. http://dx.doi.org.ezproxy.library.yorku.ca/10.1177/1368430215583517

Feeney, B. C., \& Lemay, E. P., Jr. (2012). Surviving relationship threats: The role of emotional capital. Personality and Social Psychology Bulletin, 38, 1004-1017.

Fergus, K. D., \& Reid, D. W. (2001). The couple's mutual identity and reflexivity: A systemic constructivist approach to the integration of persons and systems. Journal of Psychotherapy Integration, 11(3), 385-410. https://doi.org/10.1023/A:1016658301629

Fletcher, G. J., Simpson, J. A., \& Thomas, G. (2000). The measurement of perceived relationship quality components: A confirmatory factor analytic approach. Personality and Social Psychology Bulletin, 26(3), 340-354. http://dx.doi.org/10.1177/0146167200265007 
Furnham, A., \& Bochner, S. (1982). Social difficulty in a foreign culture: An empirical analysis. In S. Bochner (Ed.), Cultures in contact: Studies in cross-cultural interaction (pp. 161198). Oxford, UK: Pergamon.

Gable, S. L., \& Haidt, J. (2005). What (and why) is positive psychology? Review of General Psychology, 9(2), 103-110.

Gable, S. L., Reis, H. T., Impett, E. A., \& Asher, E. R. (2004). What do you do when things go right? The intrapersonal and interpersonal benefits of sharing positive events. Journal of Personality and Social Psychology, 87(2), 228.

Gaines, S. O., Jr. (1997). Communalism and the reciprocity of affection and respect among interracial married couples. Journal of Black Studies, 27, 352-364.

Gaines, S. O., Jr., \& Agnew, C. R. (2003). Relationship maintenance in intercultural couples: An interdependence analysis. In D. J. Canary \& M. Dainton (Eds.), Maintaining relationships through communication: Relational, contextual, and cultural variations (pp. 231-253). Mahwah, NJ: Lawrence Erlbaum.

Gaines, S. O., Jr., Clark, E. M., \& Afful, S. E. (2015). Interethnic marriage in the united states: An introduction. Journal of Social Issues, 71(4), 647-658. http://dx.doi.org.ezproxy.library.yorku.ca/10.1111/josi.12141

Ham, M. D. (2003). Asian American intermarriage: A socio-political construction and a treatment dilemma. Journal of Couple and Relationship Therapy, 2(2), 151-162.

Harasymchuk, C., Muise, A., Bacev-Giles, C., Gere, J., \& Impett, E. A. (2020). Broadening your horizon one day at a time: Relationship goals and exciting activities as daily antecedents of relational self-expansion. Journal of Social and Personal Relationships, 37(6), 19101926. https://doi.org/10.1177/0265407520911202 
Herman, M. R., \& Campbell, M. E. (2012). I wouldn’t, but you can: Attitudes toward interracial relationships. Social Science Research, 41(2), 343-358.

Holoien, D. S., Bergsieker, H. B., Shelton, J. N., \& Alegre, J. M. (2015). Do you really understand? Achieving accuracy in interracial relationships. Journal of Personality and Social Psychology, 108(1), 76-92. https://doi.org/10.1037/pspi0000003

Karis, T. A., \& Killian, K. D. (Eds.) (2011). Intercultural couples: Exploring diversity in intimate relationships. New York: Routledge Press.

Kenny, D. A., Kashy, D. A., \& Cook, W. L. (2006). The analysis of dyadic data. New York, NY: Guilford Press.

Killian, K. D. (2001). Reconstituting racial histories and identities: The narratives of interracial couples. Journal of Marital and Family Therapy, 27, 27-42. http://dx.doi.org.ezproxy.library.yorku.ca/10.1111/j.1752-0606.2001.tb01137.x

Killian, K. D. (2013). Interracial couples, intimacy, and therapy: Crossing racial borders. Columbia University Press, New York, NY.

Laurenceau, J.-P., Barrett, L. F., \& Pietromonaco, P. R. (1998). Intimacy as an interpersonal process: The importance of self-disclosure, partner disclosure, and perceived partner responsiveness in interpersonal exchanges. Journal of Personality and Social Psychology, 74, 1238-1251. http://dx.doi.org/10.1037/0022-3514.74.5.1238

Lee, S., Balkin, R. S., \& Fernandez, M. A. (2017). Asian Intercultural Marriage Couples in the United States: A Study in Acculturation and Personality Traits. The Family Journal, 25(2), 164-169. https://doi.org/10.1177/1066480717697951

Leslie, L. A., \& Letiecq, B. L. (2004). Marital quality of African American and white partners in interracial couples. Personal Relationships, 11(4), 559-574. https://doi.org/10.1111/j.1475$\underline{6811.2004 .00098 . x}$ 
Levin, S., Taylor, P. L., \& Caudle, E. (2007). Interethnic and interracial dating in college: A longitudinal study. Journal of Social and Personal Relationships, 24(3), 323-341.

Lewandowski, G. W., Jr., \& Aron, A. (2002, February). The Self-Expansion Scale: Construction and validation. Paper presented at the Third Annual Meeting of the Society of Personality and Social Psychology, Savannah, GA.

Lewandowski, G.W., Jr., \& Ackerman, R. A. (2006). Something's missing: Need fulfillment and self-expansion as predictors of susceptibility to infidelity. The Journal of Social Psychology, 146(4), 389-403.

\section{http://dx.doi.org.ezproxy.library.yorku.ca/10.3200/SOCP.146.4.389-403}

Lu, C., \& Wan, C. (2018). Cultural self-awareness as awareness of culture's influence on the self: Implications for cultural identification and well-being. Personality and Social Psychology Bulletin, 44(6), 823-837. http://dx.doi.org.ezproxy.library.yorku.ca/10.1177/0146167217752117

Lu, J. G., Hafenbrack, A. C., Eastwick, P. W., Wang, D. J., Maddux, W. W., \& Galinsky, A. D. (2017). "Going out" of the box: Close intercultural friendships and romantic relationships spark creativity, workplace innovation, and entrepreneurship. Journal of Applied Psychology, 102(7), 1091-1108. http://dx.doi.org.ezproxy.library.yorku.ca/10.1037/ap10000212

Mattingly, B. A., \& Lewandowski, G. W., Jr. (2013). The power of one: Benefits of individual self-expansion. The Journal of Positive Psychology, 8, 12-22.

Mattingly, B. A., McIntyre, K. P., Knee, C. R., \& Loving, T. J. (2019). Implicit theories of relationships and self-expansion: Implications for relationship functioning. Journal of Social and Personal Relationships, 36(6), 1579-1599. http://dx.doi.org.ezproxy.library.yorku.ca/10.1177/0265407518768079 
Muise, A., Harasymchuk, C., Day, L. C., Bacev-Giles, C., Gere, J., \& Impett, E. A. (2019). Broadening your horizons: Self-expanding activities promote desire and satisfaction in established romantic relationships. Journal of Personality and Social Psychology, 116, 237. http://dx.doi.org/10.1037/pspi0000148

Paolini, S., Wright, S. C., Dys-Steenbergen, O., \& Favara, I. (2016). Self-expansion and intergroup contact: Expectancies and motives to self-expand lead to greater interest in outgroup contact and more positive intergroup relations. Journal of Social Issues, 72(3), 450-471. http://dx.doi.org.ezproxy.library.yorku.ca/10.1111/josi.12176

Raposo, S., Rosen, N. O., \& Muise, A. (2020). Self-expansion is associated with greater relationship and sexual well-being for couples coping with low sexual desire. Journal of Social and Personal Relationships, 37(2), 602-623. https://doi.org/10.1177/0265407519875217

Reid, D. W., Dalton, E. J., Laderoute, K., Doell, F. K., \& Nguyen, T. (2006). Therapeutically induced changes in couple identity: The role of we-ness and interpersonal processing in relationship satisfaction. Genetic, Social, and General Psychology Monographs, 132(3), 241-284. https://doi.org/10.3200/MONO.132.3.241-288

Reiter, M. J., \& Gee, C. B. (2008). Open communication and partner support in intercultural and interfaith romantic relationships: A relational maintenance approach. Journal of Social and Personal Relationships, 25(4), 539-559. http://dx.doi.org.ezproxy.library.yorku.ca/10.1177/0265407508090872

Rico, B., Kreider, R. M., \& Anderson, L. (2018, July). Growth in interracial and interethnic married-couple households. U.S. Census Bureau. https://www.census.gov/library/stories/2018/07/interracial-marriages.html 
Selig, J. P., \& Preacher, K. J. (2008). Monte Carlo method for assessing mediation: An interactive tool for creating confidence intervals for indirect effects [Computer software].

Seshadri, G., \& Knudson-Martin, C. (2013). How couples manage interracial and intercultural differences: Implications for clinical practice. Journal of Marital and Family Therapy, 39(1), 43-58. http://dx.doi.org.ezproxy.library.yorku.ca/10.1111/j.1752$\underline{0606.2011 .00262 . x}$

Shenhav, S., Campos, B., \& Goldberg, W. A. (2017). Dating out is intercultural: Experience and perceived parent disapproval by ethnicity and immigrant generation. Journal of Social and Personal Relationships, 34(3), 397-422. https://doi.org/10.1177/0265407516640387

Skinner, A. L., \& Rae, J. R. (2019). A robust bias against interracial couples among white and black respondents, relative to multiracial respondents. Social Psychological and Personality Science, 10(6), 823-831. http://dx.doi.org.ezproxy.library.yorku.ca/10.1177/1948550618783713

Statistics Canada. (2011). National household survey ["Mixed unions in Canada"]. Retrieved from https://www12.statcan.gc.ca/nhs-enm/2011/as-sa/99-010-x/99-010-x2011003_3$\underline{\text { eng.cfm }}$

Ting-Toomey, S. (2011). A mindful approach to managing conflict in intercultural intimate couples. In T. A. Karis\& K. D. Killian (Eds.). Intercultural couples: Exploring diversity in intimate relationships (pp. 31-49). New York: Routledge Press.

Troy, A. B., Lewis-Smith, J., \& Laurenceau, J. (2006). Interracial and intraracial romantic relationships: The search for differences in satisfaction, conflict, and attachment style. Journal of Social and Personal Relationships, 23(1), 65-80. http://dx.doi.org.ezproxy.library.yorku.ca/10.1177/0265407506060178 
Walsh, C. M., Neff, L. A., \& Gleason, M. E. (2017). The role of emotional capital during the early years of marriage: Why everyday moments matter. Journal of Family Psychology, $31,513$.

Wang, H., Kao, G., \& Joyner, K. (2006). Stability of interracial and intraracial romantic relationships among adolescents. Social Science Research, 35(2), 435-453. http://dx.doi.org.ezproxy.library.yorku.ca/10.1016/j.ssresearch.2004.10.001

Yampolsky, M. A., Amiot, C. E., \& de la Sablonnière, R. (2013). Multicultural identity integration and well-being: A qualitative exploration of variations in narrative coherence and multicultural identification. Frontiers in Psychology, 4(126), 1-15. https://doi.org/10.3389/fpsyg.2013.00126

Yampolsky, M. A., Amiot, C. E., \& de la Sablonnière, R. (2016). The Multicultural Identity Integration Scale (MULTIIS): Developing a comprehensive measure for configuring one's multiple cultural identities within the self. Cultural Diversity and Ethnic Minority Psychology, 22(2), 166-184. http://dx.doi.org.ezproxy.library.yorku.ca/10.1037/cdp0000043

Yampolsky, M. A., West, A. L., Zhou, B., Muise, A., \& Lalonde, R. N. (2020). Divided Together: How Marginalization of Intercultural Relationships Is Associated with Identity Integration and Relationship Quality. Social Psychological and Personality Science. https://doi.org/10.1177/1948550620962653 


\section{Tables and Figures}

\section{Table 1}

Self-Expansion and Relationship Quality in Study 1: Means, Standard Deviations, and Correlations/Partial Correlations

\begin{tabular}{|c|c|c|c|c|c|c|c|c|}
\hline Variables & $M$ & $S D$ & 1 & 2 & 3 & 4 & 5 & 6 \\
\hline $\begin{array}{l}\text { 1. Relational } \\
\text { self-expansion }\end{array}$ & 5.05 & 0.96 & & & & & & \\
\hline $\begin{array}{l}\text { 2. Cultural } \\
\text { self-expansion }\end{array}$ & 4.97 & 1.06 & $.67 * *$ & & & & & \\
\hline 3. Satisfaction & 5.78 & 1.32 & $\begin{array}{l}.64 * * \\
(.57 * *)\end{array}$ & $\begin{array}{l}.37 * * \\
(-.09)\end{array}$ & & & & \\
\hline 4. Conflict & 3.99 & 1.69 & $\begin{array}{l}-.34 * * \\
(-.35 * *)\end{array}$ & $\begin{array}{l}-.13 * \\
(.14 *)\end{array}$ & $-.58 * *$ & & & \\
\hline $\begin{array}{l}\text { 5. Cultural } \\
\text { Conflict }\end{array}$ & 2.60 & 1.61 & $\begin{array}{l}-.26 * * \\
(-.25 * *)\end{array}$ & $\begin{array}{l}-.11 \\
(.09)\end{array}$ & $-.39 * *$ & $.53 * *$ & & \\
\hline $\begin{array}{l}\text { 6. Identity } \\
\text { Integration }\end{array}$ & 4.70 & 1.18 & $\begin{array}{l}.36 * * \\
(.20 *)\end{array}$ & $\begin{array}{l}.33 * * \\
(.12)\end{array}$ & $.35 * *$ & $-.19 * *$ & $-.19 * *$ & \\
\hline 7. Cultural Inclusion & 5.70 & .91 & $\begin{array}{l}.42 * * \\
(.31 * *)\end{array}$ & $\begin{array}{l}.29 * * \\
(.02)\end{array}$ & $.50 * *$ & $-.37 * *$ & $-.60 * *$ & $.38^{* *}$ \\
\hline
\end{tabular}

Note. Coefficients in parentheses are partial correlation for either relational self-expansion or cultural self-expansion controlling for the other. Bolded coefficients are statistically significant; $* p<.05, * * p<.01$ 


\section{Table 2}

Unstandardized Regression Coefficients for Mediated Associations Between Two Types of SelfExpansion and Relationship Quality Via Identity Integration and Cultural Inclusion in Study 1

\begin{tabular}{|c|c|c|c|c|c|c|}
\hline & $\begin{array}{c}\text { Indirect effect } \\
\text { (mediated by } \\
\text { identity } \\
\text { integration) }\end{array}$ & $S E$ & $95 \% \mathrm{CI}$ & $\begin{array}{c}\text { Indirect effect } \\
\text { (mediated by } \\
\text { cultural } \\
\text { inclusion) }\end{array}$ & $S E$ & $95 \%$ CI \\
\hline \multicolumn{7}{|l|}{$\begin{array}{l}\text { Relational Self- } \\
\text { Expansion }\end{array}$} \\
\hline Satisfaction & .07 & .03 & {$[.01, .13]$} & .16 & .05 & {$[.07, .28]$} \\
\hline Conflict & -.05 & .05 & {$[-.14, .04]$} & -.41 & .11 & {$[-.35,-.07]$} \\
\hline Cultural Conflict & -.07 & .04 & {$[-.15, .01]$} & -.41 & .10 & {$[-.62,-.22]$} \\
\hline \multicolumn{7}{|l|}{$\begin{array}{l}\text { Cultural Self- } \\
\text { Expansion }\end{array}$} \\
\hline Satisfaction & .10 & .03 & {$[.05, .17]$} & .16 & .06 & {$[.06, .28]$} \\
\hline Conflict & -.09 & .04 & {$[-.17,-.02]$} & -.17 & .06 & {$[-.30,-.06]$} \\
\hline Cultural Conflict & -.09 & .04 & {$[-.16,-.02]$} & -.28 & .09 & {$[-.47,-.11]$} \\
\hline
\end{tabular}

Note. Bolded 95\% CIs do not contain zero and are significant. 


\section{Table 3}

Unstandardized Regression Coefficients for Mediated Associations Between Two Types of SelfExpansion (Entered Simultaneously) and Relationship Quality Via Identity Integration and Cultural Inclusion in Study 1

\begin{tabular}{|c|c|c|c|c|c|c|}
\hline & $\begin{array}{c}\text { Indirect effect } \\
\text { (mediated by } \\
\text { identity } \\
\text { integration) }\end{array}$ & $S E$ & $95 \%$ CI & $\begin{array}{c}\text { Indirect effect } \\
\text { (mediated by } \\
\text { cultural inclusion) }\end{array}$ & $S E$ & $95 \%$ CI \\
\hline \multicolumn{7}{|l|}{$\begin{array}{l}\text { Relational Self- } \\
\text { Expansion } \\
\text { (controlling for } \\
\text { cultural self- } \\
\text { expansion) }\end{array}$} \\
\hline Satisfaction & .05 & .03 & {$[.01, .11]$} & .16 & .05 & {$[.07, .28]$} \\
\hline Conflict & -.04 & .04 & {$[-.13, .01]$} & -.19 & .07 & {$[-.35,-.06]$} \\
\hline Cultural Conflict & -.05 & .04 & {$[-.14, .00]$} & -.41 & .12 & {$[-.65,-.20]$} \\
\hline \multicolumn{7}{|l|}{$\begin{array}{l}\text { Cultural Self- } \\
\text { Expansion } \\
\text { (controlling for } \\
\text { relational self- } \\
\text { expansion) }\end{array}$} \\
\hline Satisfaction & .03 & .02 & {$[-.00, .08]$} & .01 & .03 & {$[-.05, .07]$} \\
\hline Conflict & -.03 & .03 & {$[-.09, .01]$} & -.01 & .04 & {$[-.08, .06]$} \\
\hline Cultural Conflict & -.03 & .02 & {$[-.08, .01]$} & -.02 & .08 & {$[-.18, .12]$} \\
\hline
\end{tabular}

Note. Bolded 95\% CIs do not contain zero and are significant. 


\section{Figure 1}

An Example Mediation Model from Study 1

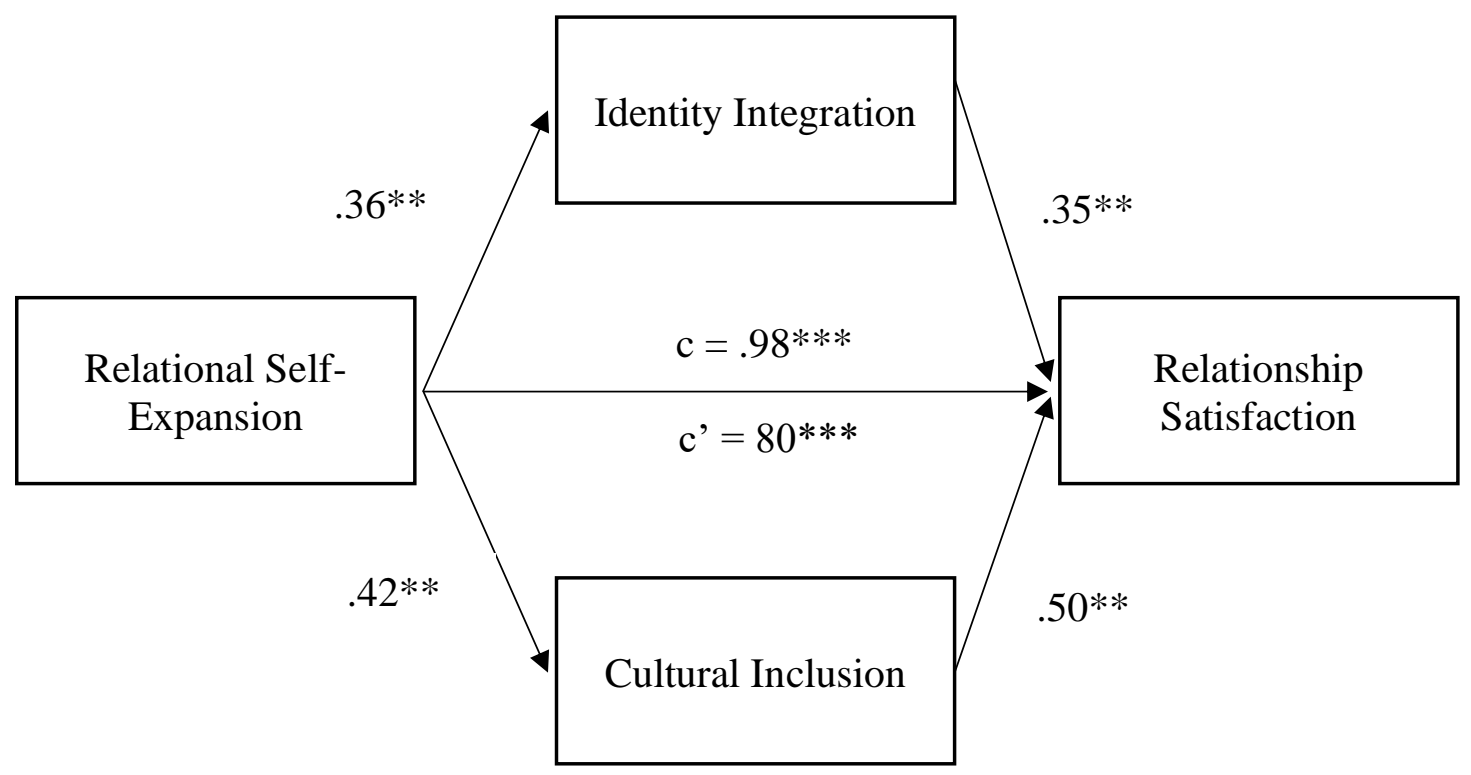

Note. Identity integration and cultural inclusion are mediators between relational selfexpansion and relationship satisfaction in Study 1. Bolded coefficients are significant, and the following denote $* p<.05, * * p<.01 * * p<.001$. Indirect effects through identity integration $(95 \%$ CI $[.01, .13])$ and cultural inclusion (95\% CI [.07, .28] were significant. 


\section{Table 4}

Self-Expansion and Relationship Quality in Study 2: Means, Standard Deviations, and Correlations/Partial Correlations

\begin{tabular}{|c|c|c|c|c|c|c|c|c|c|}
\hline Variables & $M$ & $S D$ & 1 & 2 & 3 & 4 & 5 & 6 & 7 \\
\hline $\begin{array}{l}\text { 1. Relational } \\
\text { self-expansion }\end{array}$ & 5.26 & .99 & $\begin{array}{c}.38 * * \\
(.25 * *)\end{array}$ & $\begin{array}{l}.31 * * \\
(.11)\end{array}$ & $\begin{array}{r}.25 * * \\
(.17 * *)\end{array}$ & $\begin{array}{c}-.11 \\
(-.10)\end{array}$ & $\begin{array}{c}-.08 \\
(-.06)\end{array}$ & $\begin{array}{r}.09 \\
(.04)\end{array}$ & $\begin{array}{r}.19 * * \\
(.15 * *)\end{array}$ \\
\hline $\begin{array}{l}\text { 2. Cultural } \\
\text { self-expansion }\end{array}$ & 4.89 & 1.21 & $.68 * *$ & $\begin{array}{c}.33 * * \\
(.17 * *)\end{array}$ & $\begin{array}{l}.18 * * \\
(.01)\end{array}$ & $\begin{array}{l}-.05 \\
(.03)\end{array}$ & $\begin{array}{l}-.05 \\
(.01)\end{array}$ & $\begin{array}{c}.09 \\
(.04)\end{array}$ & $\begin{array}{r}.12 * \\
(-.01)\end{array}$ \\
\hline 3. Satisfaction & 6.10 & 1.09 & $\begin{array}{c}.55 * * \\
(.46 * *)\end{array}$ & $\begin{array}{l}.34 * * \\
(-.09)\end{array}$ & $.47 * *$ & $-.36 * *$ & $-.23 * *$ & $.18 * *$ & $.32 * *$ \\
\hline 4. Conflict & 3.89 & 1.56 & $\begin{array}{c}-.23 * * \\
(-.18 * *)\end{array}$ & $\begin{array}{c}-.15 * * \\
(.03)\end{array}$ & $-.57 * *$ & $.54 * *$ & $.41 * *$ & -.09 & $-.38 * *$ \\
\hline $\begin{array}{l}\text { 5. Cultural } \\
\text { Conflict }\end{array}$ & 2.50 & 1.53 & $\begin{array}{c}-16 * * \\
(-.19 * *)\end{array}$ & $\begin{array}{c}-.04 \\
(.15 * *)\end{array}$ & $-.39 * *$ & $.61 * *$ & $.48 * *$ & $-.17 * *$ & $-.44 * *$ \\
\hline 6. Identity integration & 4.23 & .90 & $\begin{array}{l}.24 * * \\
(.06)\end{array}$ & $\begin{array}{c}.29 * * \\
(.19 * *)\end{array}$ & $.21 * *$ & -.11 & -.10 & $.28 * *$ & $.20 * *$ \\
\hline 7. Cultural inclusion & 5.77 & .79 & $\begin{array}{c}.28 * * \\
(.22 * *)\end{array}$ & $\begin{array}{l}.19 * * \\
(-.03)\end{array}$ & $.49 * *$ & $-.48 * *$ & $-.58 * *$ & $.36 * *$ & $.48 * *$ \\
\hline \multicolumn{10}{|l|}{$\underline{\text { Time } 2 \text { Results }}$} \\
\hline $\begin{array}{l}\text { 1. Relational } \\
\text { self-expansion }\end{array}$ & 5.33 & .95 & $\begin{array}{c}.51 * * \\
(.34 * *)\end{array}$ & $.43 * *$ & $(.24 * *)$ & $\begin{array}{l}-.17 * \\
(-.01)\end{array}$ & $\begin{array}{l}-.13 \\
(.02)\end{array}$ & $(-.01)$ & $\begin{array}{l}.23^{* * *} \\
(.03)\end{array}$ \\
\hline $\begin{array}{l}\text { 2. Cultural } \\
\text { self-expansion }\end{array}$ & 4.88 & 1.24 & $.69 * *$ & $\left(.33^{* *}\right)$ & $(.11)$ & $\begin{array}{l}-.23 * * \\
(-.17)\end{array}$ & $\begin{array}{l}-.21 * \\
(-.16)\end{array}$ & $\left(.33^{* * *}\right)$ & $(.20 *)$ \\
\hline 3. Satisfaction & 6.03 & 1.27 & $\begin{array}{c}.56 * * \\
(.50 * *)\end{array}$ & $\begin{array}{l}.34 * * \\
(-.07)\end{array}$ & $.66 * *$ & $-.42 * *$ & $-.24 * *$ & $.30 * *$ & $.37 * *$ \\
\hline 4. Conflict & 3.79 & 1.72 & $\begin{array}{c}-.28 * * \\
(-.13)\end{array}$ & $\begin{array}{l}-.18 * \\
(-.07)\end{array}$ & $-.57 * *$ & $-.60 * *$ & $.44 * *$ & $-.22 *$ & $-.42 * *$ \\
\hline $\begin{array}{l}\text { 5. Cultural } \\
\text { Conflict }\end{array}$ & 2.48 & 1.59 & $\begin{array}{c}-.11 \\
(-.07)\end{array}$ & $\begin{array}{c}-.08 \\
(-.02)\end{array}$ & $-.30 * *$ & $.60 * *$ & $.53 * *$ & $-.36 * *$ & $-.65 * *$ \\
\hline 6. Identity integration & 4.17 & .94 & $\begin{array}{l}.30 * * \\
(.12)\end{array}$ & $\begin{array}{c}.34 * * \\
(.24 * *)\end{array}$ & $.38 * *$ & $-.22 * *$ & $-.36 * *$ & $.43 * *$ & $.37 * *$ \\
\hline 7. Cultural inclusion & 5.65 & .79 & $\begin{array}{c}.35 * * \\
(.26 * *)\end{array}$ & $\begin{array}{l}.28 * * \\
(.08)\end{array}$ & $.54 * *$ & $-.50 * *$ & $-.65 * *$ & $.52 * *$ & $.49 * *$ \\
\hline
\end{tabular}

Note. Coefficients in parentheses are partial correlation for either relational self-expansion or cultural self-expansion controlling for the other. Bolded coefficients are statistically significant; $* p<.05, * * p<.01$. Coefficients on the diagonal indicate correlations and partial correlations between the partner values from each row and the actor values from each column. 


\section{Table 5}

Total, Direct, and Indirect Effects for Models with Identity Integration/Cultural Inclusion Mediating the Association Between SelfExpansion/Cultural Self-Expansion and Relationship Quality in Study 2, time 1

\begin{tabular}{|c|c|c|c|c|c|c|c|c|c|c|}
\hline Effects & $\begin{array}{l}\text { Actor's } \\
\text { identity } \\
\text { integratio } \\
n\end{array}$ & $\begin{array}{l}\text { Partner's } \\
\text { identity } \\
\text { integration }\end{array}$ & $\begin{array}{l}\text { Actor's } \\
\text { cultural } \\
\text { inclusion }\end{array}$ & $\begin{array}{l}\text { Partner's } \\
\text { cultural } \\
\text { inclusion }\end{array}$ & $\begin{array}{l}\text { Actor's } \\
\text { relationship } \\
\text { satisfaction }\end{array}$ & $\begin{array}{l}\text { Actor's } \\
\text { conflict }\end{array}$ & $\begin{array}{l}\text { Actor's } \\
\text { cultural } \\
\text { conflict }\end{array}$ & $\begin{array}{l}\text { Partner's } \\
\text { relationship } \\
\text { satisfaction }\end{array}$ & $\begin{array}{l}\text { Partner's } \\
\text { conflict }\end{array}$ & $\begin{array}{l}\text { Partner's } \\
\text { cultural } \\
\text { conflict }\end{array}$ \\
\hline \multicolumn{11}{|l|}{ Self-Expansion } \\
\hline Total effect & $.21 * * *$ & .003 & $.19 * * *$ & .08 & $.58 * * *(.05)$ & $-.34 * * *(.08)$ & $-.23 * *(.08)$ & $.05(.05)$ & $-.05(.08)$ & $-.04(.08)$ \\
\hline $\begin{array}{l}\text { Direct effect } \\
\text { (controlling for } \\
\text { integration) }\end{array}$ & - & & - & & $.56 * * *(.05)$ & $-.32 * * *(.09)$ & $-.21 *(.09)$ & $.02(.05)$ & $.03(.09)$ & $-.03(.09)$ \\
\hline $\begin{array}{l}\text { Direct effect } \\
\text { (controlling for } \\
\text { inclusion) }\end{array}$ & & & & & $.49 * * *(.05)$ & $-.17 *(0.8)$ & $-0.01(.07)$ & $-0.01(0.5)$ & $.09(.08)$ & $.13(.07)$ \\
\hline $\begin{array}{l}\text { Indirect effect mediated } \\
\text { by actor's integration }\end{array}$ & - & & - & & {$[-.01, .04]$} & {$[-.06, .02]$} & {$[-.06, .02]$} & {$[.004, .06]$} & {$[-.06, .02]$} & {$[-.11,-.01]$} \\
\hline $\begin{array}{l}\text { Indirect effect mediated } \\
\text { by actor's inclusion }\end{array}$ & - & & - & & {$[.04, .13]$} & {$[-.21,-.07]$} & {$[-.26,-.09]$} & {$[-.002, .05]$} & {$[-.14,-.03]$} & {$[-.15,-.04]$} \\
\hline \multicolumn{11}{|l|}{$\begin{array}{l}\text { Cultural self- } \\
\text { expansion }\end{array}$} \\
\hline Total effect & $.22 * * *$ & -.005 & $.10 * *$ & .04 & $.27 * * *(.05)$ & $-.17 *(.07)$ & $.02(.07)$ & $.07(.05)$ & $-.02(.07)$ & $-.06(.07)$ \\
\hline $\begin{array}{l}\text { Direct effect } \\
\text { (controlling for } \\
\text { integration) }\end{array}$ & - & & - & & $.24 * * *(.05)$ & $-.14(.07)$ & $.05(.07)$ & $.04(.05)$ & $-.01(.07)$ & $.00(.07)$ \\
\hline $\begin{array}{l}\text { Direct effect } \\
\text { (controlling for } \\
\text { inclusion) }\end{array}$ & & & & & $.21 * * *(04)$ & $-.08(.06)$ & $.13 *(.06)$ & $.03(.04)$ & $.05(.06)$ & $.03(.06)$ \\
\hline $\begin{array}{l}\text { Indirect effect mediated } \\
\text { by actor's integration }\end{array}$ & - & & - & & {$\left[5.31 \mathrm{e}^{-05}, .06\right]$} & {$[-.07, .02]$} & {$[-.08, .01]$} & {$[.002, .06]$} & {$[-.07, .02]$} & {$[-.11,-.01]$} \\
\hline $\begin{array}{l}\text { Indirect effect mediated } \\
\text { by actor's inclusion }\end{array}$ & - & & - & & {$[0.01, .09]$} & {$[-.13,-.02]$} & {$[-.16,-.03]$} & {$[-.0005, .03]$} & {$[-.04, .01]$} & {$[-.82,-.01]$} \\
\hline
\end{tabular}




\section{Table 6}

Total, Direct, and Indirect Effects for Models with Identity Integration/Cultural Inclusion Mediating the Association Between SelfExpansion and Cultural Self-Expansion (entered simultaneously) and Relationship Quality in Study 2, time 1

\begin{tabular}{|c|c|c|c|c|c|c|c|c|c|c|}
\hline Effects & $\begin{array}{l}\text { Actor's } \\
\text { identity } \\
\text { integratio } \\
\mathrm{n}\end{array}$ & $\begin{array}{l}\text { Partner's } \\
\text { identity } \\
\text { integration }\end{array}$ & $\begin{array}{l}\text { Actor's } \\
\text { cultural } \\
\text { inclusion }\end{array}$ & $\begin{array}{l}\text { Partner's } \\
\text { cultural } \\
\text { inclusion }\end{array}$ & $\begin{array}{l}\text { Actor's } \\
\text { relationship } \\
\text { satisfaction }\end{array}$ & $\begin{array}{l}\text { Actor's } \\
\text { conflict }\end{array}$ & $\begin{array}{l}\text { Actor's } \\
\text { cultural } \\
\text { conflict }\end{array}$ & $\begin{array}{l}\text { Partner's } \\
\text { relationship } \\
\text { satisfaction }\end{array}$ & $\begin{array}{l}\text { Partner's } \\
\text { conflict }\end{array}$ & $\begin{array}{l}\text { Partner's } \\
\text { cultural } \\
\text { conflict }\end{array}$ \\
\hline \multicolumn{11}{|l|}{ Self-Expansion } \\
\hline Total effect & .06 & -.00 & $.22 * *$ & .10 & $.66 * * *(.07)$ & $-.38 * *(.12)$ & $-.43 * * * *(.11)$ & $.06(.07)$ & $-.11(.12)$ & $-.04(.11)$ \\
\hline $\begin{array}{l}\text { Direct effect } \\
\text { (controlling for } \\
\text { integration) }\end{array}$ & - & - & - & - & $.65 * * *(.07)$ & $-.37 * *(.12)$ & $-.41 * * *(.11)$ & $.05(.07)$ & $-.10(.12)$ & $-.02(.11)$ \\
\hline $\begin{array}{l}\text { Direct effect } \\
\text { (controlling for } \\
\text { inclusion) }\end{array}$ & - & - & - & - & $.55^{* * * *(.07)}$ & $-.19(.11)$ & $-.28(.10)$ & $-.005(.07)$ & $.05(.11)$ & $.15(.10)$ \\
\hline $\begin{array}{l}\text { Indirect effect mediated } \\
\text { by actor's integration }\end{array}$ & - & - & - & - & & & & & & \\
\hline $\begin{array}{l}\text { Indirect effect mediated } \\
\text { by actor's inclusion }\end{array}$ & - & - & - & - & {$[.05, .19]$} & & & & & \\
\hline \multicolumn{11}{|l|}{$\begin{array}{l}\text { Cultural self- } \\
\text { expansion }\end{array}$} \\
\hline Total effect & $.19 * *$ & -.01 & -.03 & -.02 & $-.09(.06)$ & $.05(.10)$ & $.25^{* *}(.09)$ & $-.01(.06)$ & $.07(.10)$ & $-.05(.11)$ \\
\hline $\begin{array}{l}\text { Direct effect } \\
\text { (controlling for } \\
\text { integration) }\end{array}$ & - & - & - & - & $-.11(.06)$ & $-.07(.10)$ & $.27 * *(.09)$ & $-.04(.06)$ & $-.09(.10)$ & $.04(.09)$ \\
\hline $\begin{array}{l}\text { Direct effect } \\
\text { (controlling for } \\
\text { inclusion) }\end{array}$ & - & - & - & - & $-.08(.05)$ & $.02(.09)$ & $.21 * *(.08)$ & $.001(.05)$ & $.04(.09)$ & $-.04(.08)$ \\
\hline $\begin{array}{l}\text { Indirect effect mediated } \\
\text { by actor's integration }\end{array}$ & - & - & - & - & & & {$[.012, .11]$} & & & \\
\hline $\begin{array}{l}\text { Indirect effect mediated } \\
\text { by actor's inclusion }\end{array}$ & - & - & - & - & & & & & & \\
\hline
\end{tabular}




\section{Table 7}

Total, Direct, and Indirect Effects for Models with Identity Integration/Cultural Inclusion Mediating the Association Between SelfExpansion/Cultural Self-Expansion and Relationship Quality in Study 2 Over time.

\begin{tabular}{|c|c|c|c|c|c|c|c|c|c|c|}
\hline Effects & $\begin{array}{l}\text { T2 } \\
\text { Actor's } \\
\text { identity } \\
\text { integratio } \\
\mathrm{n}\end{array}$ & $\begin{array}{l}\text { T2 } \\
\text { Partner's } \\
\text { identity } \\
\text { integratio } \\
\mathrm{n}\end{array}$ & $\begin{array}{l}\text { T2 } \\
\text { Actor's } \\
\text { cultural } \\
\text { inclusion }\end{array}$ & $\begin{array}{l}\text { T2 Partner's } \\
\text { cultural } \\
\text { inclusion }\end{array}$ & $\begin{array}{l}\text { T2 Actor's } \\
\text { relationship } \\
\text { satisfaction }\end{array}$ & $\begin{array}{l}\text { T2 Actor's } \\
\text { conflict }\end{array}$ & $\begin{array}{l}\text { T2 Actor's } \\
\text { cultural } \\
\text { conflict }\end{array}$ & $\begin{array}{l}\text { T2 Partner's } \\
\text { relationship } \\
\text { satisfaction }\end{array}$ & $\begin{array}{l}\text { T2 Partner's } \\
\text { conflict }\end{array}$ & $\begin{array}{l}\text { T2 Partner's } \\
\text { cultural } \\
\text { conflict }\end{array}$ \\
\hline \multicolumn{11}{|l|}{ Self-Expansion } \\
\hline Total effect & $\begin{array}{l}.10(.0 \\
7)\end{array}$ & $.14 *(.06)$ & $.06(.04)$ & $.003(.04)$ & $-.10(.08)$ & $-.01 *(.10)$ & $.15(.10)$ & $.21 * *(.06)$ & $-.18(.10)$ & $-.19(.09)$ \\
\hline $\begin{array}{l}\text { Direct effect } \\
\text { (controlling for } \\
\text { integration) }\end{array}$ & - & - & - & - & $-.12(.08)$ & $-.00(.11)$ & $.22 *(.10)$ & $.20 * *(.07)$ & $-.17(.10)$ & $-.14(.09)$ \\
\hline $\begin{array}{l}\text { Direct effect } \\
\text { (controlling for } \\
\text { inclusion) }\end{array}$ & - & - & - & - & $-.11(.08)$ & $.03(.10)$ & $.24 *(.10)$ & $.19 * *(.07)$ & $-.14(.10)$ & $-.09(.09)$ \\
\hline $\begin{array}{l}\text { Indirect effect mediated } \\
\text { by actor's integration }\end{array}$ & - & - & - & - & & & {$[-0.076,0.002]$} & & & \\
\hline $\begin{array}{l}\text { Indirect effect mediated } \\
\text { by actor's inclusion }\end{array}$ & - & - & - & - & & & & & & \\
\hline \multicolumn{11}{|l|}{$\begin{array}{l}\text { Cultural self- } \\
\text { expansion }\end{array}$} \\
\hline Total effect & $\begin{array}{c}.08(.0 \\
5)\end{array}$ & $.15 * *(.05)$ & $.01(.04)$ & $.03(.03)$ & $-.05(.06)$ & $.06(.08)$ & $.06(.08)$ & $.07(.05)$ & $-.16 *(.08)$ & $-.17 *(.08)$ \\
\hline $\begin{array}{l}\text { Direct effect } \\
\text { (controlling for } \\
\text { integration) }\end{array}$ & - & - & - & - & $-.07(.06)$ & $.07(.08)$ & $.11(.08)$ & $.06(.06)$ & $-.15(.08)$ & $-.13(.08)$ \\
\hline $\begin{array}{l}\text { Direct effect } \\
\text { (controlling for } \\
\text { inclusion) }\end{array}$ & - & - & - & - & $-.05(.05)$ & $.08(.08)$ & $.12(.07)$ & $.05(.05)$ & $-.13(.08)$ & $-.11(.07)$ \\
\hline $\begin{array}{l}\text { Indirect effect mediated } \\
\text { by actor's integration }\end{array}$ & - & - & - & - & & & {$[-0.028,0.009]$} & & & \\
\hline $\begin{array}{l}\text { Indirect effect mediated } \\
\text { by actor's inclusion }\end{array}$ & - & - & - & - & & & & & & \\
\hline
\end{tabular}




\section{Table 8}

Total, Direct, and Indirect Effects for Models with Identity Integration/Cultural Inclusion Mediating the Association Between SelfExpansion and Cultural Self-Expansion (entered simultaneously) and Relationship Quality in Study 2 Over time.

\begin{tabular}{|c|c|c|c|c|c|c|c|c|c|c|}
\hline Effects & $\begin{array}{l}\text { T2 } \\
\text { Actor's } \\
\text { identity } \\
\text { integratio } \\
\mathrm{n}\end{array}$ & $\begin{array}{l}\mathrm{T} 2 \\
\text { Partner's } \\
\text { identity } \\
\text { integratio } \\
\mathrm{n}\end{array}$ & $\begin{array}{l}\text { T2 } \\
\text { Actor's } \\
\text { cultural } \\
\text { inclusion }\end{array}$ & $\begin{array}{l}\text { T2 Partner's } \\
\text { cultural } \\
\text { inclusion }\end{array}$ & $\begin{array}{l}\text { T2 Actor's } \\
\text { relationship } \\
\text { satisfaction }\end{array}$ & $\begin{array}{l}\text { T2 Actor's } \\
\text { conflict }\end{array}$ & $\begin{array}{l}\text { T2 Actor's } \\
\text { cultural } \\
\text { conflict }\end{array}$ & $\begin{array}{l}\text { T2 Partner's } \\
\text { relationship } \\
\text { satisfaction }\end{array}$ & $\begin{array}{l}\text { T2 Partner's } \\
\text { conflict }\end{array}$ & $\begin{array}{l}\text { T2 Partner's } \\
\text { cultural } \\
\text { conflict }\end{array}$ \\
\hline \multicolumn{11}{|l|}{ Self-Expansion } \\
\hline Total effect & .05 & .005 & .09 & -.03 & $-.06(.10)$ & $-.10(.14)$ & $.19(.13)$ & $.27 * *(.09)$ & $-.11(13)$ & $-.07(.13)$ \\
\hline $\begin{array}{l}\text { Direct effect } \\
\text { (controlling for } \\
\text { integration) }\end{array}$ & - & - & - & - & $-.08(.10)$ & $-.09(.14)$ & $.23(.13)$ & $.27 * *(.09)$ & $-.11(.13)$ & $-.07(.13)$ \\
\hline $\begin{array}{l}\text { Direct effect } \\
\text { (controlling for } \\
\text { inclusion) }\end{array}$ & - & - & - & - & $-.07(.10)$ & $-.06(.14)$ & $.25(.13)$ & $.26 * *(.09)$ & $-.08(.13)$ & $.00(.12)$ \\
\hline $\begin{array}{l}\text { Indirect effect mediated } \\
\text { by actor's integration }\end{array}$ & - & - & - & - & & & & & & \\
\hline $\begin{array}{l}\text { Indirect effect mediated } \\
\text { by actor's inclusion }\end{array}$ & - & - & - & - & & & & & & \\
\hline \multicolumn{11}{|l|}{$\begin{array}{l}\text { Cultural self- } \\
\text { expansion }\end{array}$} \\
\hline Total effect & .05 & $.15 *$ & -.03 & .04 & $-.03(.07)$ & $.12(.11)$ & $-.04(.10)$ & $-.07(.07)$ & $-.11(.13)$ & $-.13(.11)$ \\
\hline $\begin{array}{l}\text { Direct effect } \\
\text { (controlling for } \\
\text { integration) }\end{array}$ & - & - & - & - & $-.04(.07)$ & $.12(.11)$ & $-.00(.10)$ & $-.09(.07)$ & $-.08(.11)$ & $-.09(.10)$ \\
\hline $\begin{array}{l}\text { Direct effect } \\
\text { (controlling for } \\
\text { inclusion) }\end{array}$ & - & - & - & - & $-.03(.07)$ & $.11(.11)$ & $-.01(.10)$ & $-.08(.07)$ & $-.08(.11)$ & $-.11(.10)$ \\
\hline $\begin{array}{l}\text { Indirect effect mediated } \\
\text { by actor's integration }\end{array}$ & - & - & - & - & & & & & & \\
\hline $\begin{array}{l}\text { Indirect effect mediated } \\
\text { by actor's inclusion }\end{array}$ & - & - & - & - & & & & & & \\
\hline
\end{tabular}




\section{Appendix: Study Materials}

Relational Self-Expansion (SEQ; Lewandowski \& Aron, 2002)
1
2
3
4
5
6
7

Not very much

Moderately

Very much

1. How much does being with your partner result in your having new experiences?

2. When you are with your partner, do you feel a greater awareness of things because of them?

3. How much does your partner increase your ability to accomplish new things?

4. How much does being with your partner make you more appealing to potential future partners?

5. How much does your partner help to expand your sense of the kind of person you are?

6. How much do you see your partner as a way to expand your own capabilities?

7. How often do you learn new things about your partner?

8. How much does your partner provide a source of exciting experiences?

9. How much do your partner's strengths as a person (skills, abilities, etc.) compensate for some of your own weaknesses as a person?

10. How much do you feel that you have a larger perspective on things because of your partner?

11. How much has being with your partner resulted in your learning new things?

12. How much has knowing your partner made you a better person?

13. How much does being with your partner increase the respect other people have for you?

14. How much does your partner increase your knowledge?

Cultural Self-Expansion in Relationship (modified from SEQ above)

$\begin{array}{lllllll}1 & 2 & 3 & 4 & 5 & 6 & 7\end{array}$

Not very much

Moderately

Very much 
1. How much does being with your partner result in your having new cultural experiences?

2. How much do you feel a greater awareness of things because of being exposed to your partner's culture(s)?

3. How much does learning about your partner's culture(s) increase your ability to accomplish new things?

4. How much does learning about your partner's culture(s) make you more appealing to potential future partners?

5. How much does learning about your partner's culture(s) help to expand your sense of the kind of person you are?

6. How much do you see your partner's culture(s) as a way to expand your own capabilities?

7. How often do you learn new things about your partner's culture(s)?

8. How much does your partner's culture(s) provide a source of exciting experiences?

9. How much do your partner's culture(s)' strengths compensate for some of your own weaknesses as a person?

10. How much do you feel that you have a larger perspective on things because of being exposed to your partner's culture(s)?

11. How much has experiencing your partner's culture(s) resulted in you learning new things?

12. How much has experiencing your partner's culture(s) made you a better person?

13. How much does learning about your partner's culture(s) increase the respect other people have for you?

14. How much does experiencing your partner's culture(s) increase your knowledge?

Couple-Cultural Identity Configurations: Modified Multicultural Identity Integration Scale (Yampolsky, Amiot, \& de la Sablonniere, 2016) 
When you're in an intercultural couple, you may be coming together with certain differences in values, norms, expectations, and ways of doing things. In this process, you and your partner might each be bringing your own different cultural identities with you into the relationship. At the same time, your romantic relationship develops its own unique form as you build a sense of "us" together- this is called your "couple identity".

Below are a series of questions about the relationship between your cultural identity and your couple identity. While completing this questionnaire, please keep the following information in mind:

Cultural identity refers to the feeling of being a member of a particular cultural group (e.g., British, Indian, Italian, Chinese), and the experience of aligning with values, beliefs, behaviours, etc. of a particular culture. If you are part of more than one cultural group, please think of all of them as your cultural identity.

Couple identity refers to you and your partner as a couple with a sense of "us" that makes your couple unique and different from other couples.

Identities refers to only your cultural identity and your couple identity.

\section{Integration items:}

My cultural and couple identities fit within a broader identity.

My cultural and couple identities are connected.

The differences between my cultural identity and couple identity complete each other.

My cultural and couple identities complement each other.

I have an identity that includes my cultural and couple identities.

My cultural and couple identities are all part of a broader group identity.

My cultural and couple identities are part of a more global identity. 
I draw similarities between my cultural identity and my couple identity.

\section{Index of Cultural Inclusion (Killian, 2013)}

The following items describe common thoughts, feelings, and experiences romantic partners have in their relationship together. Read each statement carefully, and then select the response that best reflects how much you agree or disagree with each item. 1 (strongly disagree) to 7 (strongly agree).

1. I feel very comfortable talking with my partner about the family and culture that I come from.

2. My partner feels very comfortable talking with me about the family and culture that they come from.

3. In our relationship, I can discuss my family's traditions, customs, and values frankly and openly.

4. In our relationship, my partner can discuss their family's traditions, customs, and values frankly and openly.

5. There are parts of my cultural or ethnic background that I cannot express in my relationship. (R)

6. I think there are parts of my partner's cultural or ethnic background that they cannot express in our relationship. (R)

7. In terms of my cultural background, I know that I share $100 \%$ of who I am with my partner. 8. In terms of their cultural background, I believe that my partner shares $100 \%$ of who they are with me.

9. When I share very personal things about my cultural background, I never regret it afterward. 10. When my partner shares very personal things about my cultural background, they never regret it afterward. 
11. I speak to my partner about my cultural history and identity.

12. My partner speaks to me about their cultural history and identity.

13. My partner values my cultural or ethnic beliefs and customs.

14. I value my partner's cultural beliefs and customs.

15. Sometimes my partner does not appreciate aspects of my culture. (R)

16. Sometimes I do not appreciate aspects of my partner's culture. (R)

17. I sometimes think that my partner sees their culture, traditions, and beliefs as more valuable or important than mine. $(\mathrm{R})$

18. I sometimes see my culture, traditions, and beliefs as more valuable or important than my partner's. (R)

19. My partner encourages me to include my familial and cultural traditions in our life together. 20. I encourage my partner to include their familial and cultural traditions in our life together.

21. There is little or no space in this relationship to continue my family traditions. (R)

22. There is little or no space in this relationship to continue my partner's family traditions. (R)

23. My partner accepts my introduction of cultural traditions into our life together (e.g., particular foods, music, dancing, holiday rituals, etc.).

24. I accept my partner's introduction of cultural traditions into our life together (e.g., particular foods, music, dancing, holiday rituals, etc.).

25. My cultural traditions and ways of being have been the subject of conflict. (R)

26. My partner's cultural traditions and ways of being have been the subject of conflict. (R)

Perceived Relationship Quality Component Inventory (Fletcher, Simpson, \& Thomas, 2000)

The following questions are about your relationship with your partner. Please rate each item using the scale below. $(1=$ not at all, to $7=$ extremely $)$ 


\section{Relationship Satisfaction:}

1. How satisfied are you with your relationship?

2. How content are you with your relationship?

3. How happy are you with your relationship?

Conflict Scale (Braiker \& Kelley, 1978) and modified Cultural Conflict Scale General Conflict

1. How often do you and your partner argue with each other? $(1=$ Not very often, $9=$ very often $)$

2. To what extent do you try to change things that bother you about your partner (e.g., behaviors, attitudes, etc. $) ?(1=$ Not at all, $9=$ very much so $)$

3. How often do you feel angry or resentful toward your partner? $(1=$ Not very often, $9=$ very often)

4. When you and your partner argue, how serious are the problems or arguments? $(1=$ Not serious at all, $9=$ very serious)

5. To what extent do you communicate negative feelings toward your partner (e.g., anger, dissatisfaction, frustration, etc. $) ?(1=$ Not at all, $9=$ very much so $)$

\section{Cultural Conflict}

1. How often do you and your partner argue with each other over your cultural differences? $(1=$ Not very often, $9=$ very often)

2. To what extent do you try to change things that bother you about your partner, that you believe they get from their culture (e.g., behaviors, attitudes, etc.)? $(1=$ Not at all, $9=$ very much so $)$ 3. How often do you feel angry or resentful toward your partner over cultural differences between you? $(1=$ Not very often, $9=$ very often $)$ 
4. When you and your partner argue over cultural differences, how serious are the problems or arguments? $(1=$ Not serious at all, $9=$ very serious $)$

5. To what extent do you communicate negative feelings toward your partner (e.g., anger, dissatisfaction, frustration, etc.) that are brought on by your cultural differences? $(1=$ Not at all, $9=$ very much so)

\section{Relational Self-Expansion Article}

New research at the University of Toronto found that engaging in exciting and novel activities with a romantic partner can contribute to relationship quality for cohabiting couples (i.e., couples who live together). Based on the findings of three studies, the researchers suggest that couples might improve their relationships by expanding their sense of who they are through learning about their partner.

According to this research, cohabiting romantic relationships are full of new experiences that can be exciting and interesting. To take advantage of this, couples should find novelty and seek out new experiences in their relationship. The lead researcher on the study, Dr. Emily Impett states, "In our research, we find that the cohabiting couples who seize their unique opportunities to have new and interesting experiences together, were by far the happiest and most likely to stay together over time." Dr. Impett suggests that to reap these benefits, couples should try to engage in activities together that neither partner has done before, like learning something new together, watching a documentary or trying a new cocktail recipe. "Cohabiting relationships are full of these kinds of opportunities," she says, "it's just about finding ways to take advantage of them."

\section{Cultural Self-Expansion Article}

New research at the University of Toronto found that engaging in exciting and novel cultural activities with a romantic partner can contribute to relationship quality for intercultural couples 
(i.e., couples with different cultural backgrounds). Based on the findings of three studies, the researchers suggest that couples might improve their relationships by expanding their sense of who they are through learning about their partner's culture.

According to this research, intercultural romantic relationships are full of new experiences that can be exciting and interesting. To take advantage of this, couples should find novelty and seek out new cultural experiences in their relationship. The lead researcher on the study, Dr. Emily Impett states, "In our research, we find that the intercultural couples who seize their unique opportunities to have new and interesting cultural experiences together, were by far the happiest and most likely to stay together over time." Dr. Impett suggests that to reap these benefits, couples should try to engage in cultural activities together that neither partner has done before, like learning or experiencing something new about each other's culture, watching an international film or cooking a new cultural recipe together. "Intercultural relationships are full of these kinds of opportunities," she says, "it's just about finding ways to take advantage of them." 